\title{
Potential for increased photosynthetic performance and crop productivity in response to climate change: role of CBFs and gibberellic acid
}

\section{Norman P. A. Hüner ${ }^{1 *}$, Keshav Dahal ${ }^{2}$, Leonid V. Kurepin ${ }^{1}$, Leonid Savitch ${ }^{3}$, Jas Singh ${ }^{3}$, Alexander G. Ivanov' ${ }^{1}$ Khalil Kane ${ }^{4}$ and Fathey Sarhan ${ }^{4}$}

\author{
1 Biology Department and the Biotron Centre for Experimental Climate Change Research, University of Western Ontario, London, ON, Canada \\ ${ }^{2}$ Department of Biological Sciences, University of Toronto at Scarborough, Scarborough, ON, Canada \\ ${ }^{3}$ Eastern Cereal and Oilseed Research Centre, Agriculture and Agri-Food Canada, Ottawa, ON, Canada \\ ${ }^{4}$ Départment des Sciences biologiques, Université du Québec à Montréal, Montréal, OC, Canada
}

Edited by:

Matteo Balderacchi, Università

Cattolica del Sacro Cuore, Italy

Reviewed by:

Peter Horton, University of

Sheffield, UK

Michael Wisniewski, United States

Department of Agriculture, USA

\section{${ }^{*}$ Correspondence:}

Norman P. A. Hüner, Department of Biology, Rm 301J NCB, University of Western Ontario, North Campus

Bldg., 1151 Richmond St. N.,

London, ON N6A 5B7, Canada

e-mail:nhuner@uwo.ca
We propose that targeting the enhanced photosynthetic performance associated with the cold acclimation of winter cultivars of rye (Secale cereale L.), wheat (Triticum aestivum L.), and Brassica napus L. may provide a novel approach to improve crop productivity under abiotic as well as biotic stress conditions. In support of this hypothesis, we provide the physiological, biochemical, and molecular evidence that the dwarf phenotype induced by cold acclimation is coupled to significant enhancement in photosynthetic performance, resistance to photoinhibition, and a decreased dependence on photoprotection through non-photochemical quenching which result in enhanced biomass production and ultimately increased seed yield. These system-wide changes at the levels of phenotype, physiology, and biochemistry appear to be governed by the family of C-repeat/dehydration-responsive family of transcription factors (CBF/DREB1). We relate this phenomenon to the semi-dwarf, gibberellic acid insensitive (GAl), cereal varieties developed during the "green revolution" of the early 1960s and 1970s. We suggest that genetic manipulation of the family of C-repeat/dehydration-responsive element binding transcription factors (CBF/DREB1) may provide a novel approach for the maintenance and perhaps even the enhancement of plant productivity under conditions of sub-optimal growth conditions predicted for our future climate.

Keywords: phenotypic plasticity, photosynthetic performance, crop productivity, CBFs, gibberellic acid, climate change

\section{INTRODUCTION}

The increase in the yield of major food crops since the mid1950s has been achieved mainly through genetic improvement and increased use of agricultural inputs such as fertilizers, pesticides, and water (Murchie et al., 2009). Zhu et al. (2010) have suggested that the yield of major food crops since the last decade is increasing slowly, which may indicate that yield increase due to improved agricultural practices has reached an upper theoretical limit. Thus, it appears that the further enhancement in crop yield can only be achieved by enhancing genetic yield potential, that is, the seed yield that a crop can achieve per unit ground area under optimum growth conditions without biotic and abiotic stresses. The maximum potential biomass and grain yield that a plant can produce is determined essentially by the following five yield variables: (a) the amount of incident solar radiation available over the growing season of a plant, (b) the light interception efficiency, that is, the efficiency of the photosynthetic pigments to intercept photosynthetic active radiation, (c) the energy conversion efficiency, that is, the ratio of the biomass energy produced over a given period to the radiative energy intercepted by the canopy over the same period, (d) the translocation of photosynthates to sinks, as determined by sink strength, and (e) the partitioning efficiency, that is, the amount of total biomass energy partitioned into seed production per unit ground area, also known as harvest index (HI) (Loomis and Amthor, 1999; Long et al., 2006; Zhu et al., 2010).

Since energy partitioning efficiency and light interception efficiency have approached the theoretical upper limit (Zhu et al., 2010), further increase in yield potential can only be achieved by an increase in the energy conversion efficiency into biomass. Since plant dry matter consists of about $40 \%$ carbon by weight, an increase in total biomass production can be achieved through enhanced photosynthetic carbon assimilation (Murchie et al., 2009). Although photosynthesis is the ultimate basis for the conversion of light energy into biomass and seed yield to date, improving photosynthetic carbon assimilation has played only a minor role in enhancing energy conversion to biomass and seed yield (Long et al., 2006; Zhu et al., 2010).

This is, in part, due to the important photoprotective mechanisms that have evolved in all photoautotrophs to protect the photosynthetic apparatus from irradiance that is in excess of that which can be utilized for either reductive $\mathrm{CO}_{2}$ assimilation as well as reductive $\mathrm{N}$ and $\mathrm{S}$ assimilation (Adams III and Demmig-Adams, 1993; Demmig-Adams and Adams III, 1996; 
Horton et al., 1996; Demmig-Adams et al., 1999; Niyogi, 1999; Horton, 2000, 2012; Horton and Ruban, 2005). Excess light is not only necessarily due to an increase in absolute actinic irradiance but is also generated with no change in absolute irradiance when coupled with either low temperature (Krause, 1994; Hüner et al., 1998; Ensminger et al., 2006; Farage et al., 2006; Takahashi and Murata, 2008; Hüner and Grodzinski, 2011) or other abiotic and biotic environmental stresses (Murata et al., 2007; Takahashi and Murata, 2008) by decreasing the photochemical efficiency of PSII. Consequently, the induction of photoprotective mechanisms to dissipate excess absorbed energy represents an important mechanism to balance the flux of energy absorbed and transformed into reducing power with the flux of energy utilized through the consumption of photosynthetically generated electrons by C, N, and S metabolism (Anderson et al., 1995; Hüner et al., 1998, 2013; Öquist and Hüner, 2003; Eberhard et al., 2008; Murchie et al., 2009; Hüner et al., 2012). Although the induction of photoprotective mechanisms reduces the efficiency of $\mathrm{CO}_{2}$ assimilation and decreases biomass production, these photoprotective mechanisms are essential for plant survival against myriad environmental stresses (Kulheim et al., 2002; Sane et al., 2012). Even though inhibition of these photoprotective mechanisms would theoretically increase energy conversion efficiency in the very short-term, this is simply not an option for longterm survival of plants exposed to environmental conditions that fluctuate on an hourly, daily, and annual basis. Photoprotection from excess irradiance is essential for maximizing plant fitness and survival (Kulheim et al., 2002).

The increase in yield potential of major crops over the past 50 years occurred, by and large, as a consequence of improved partitioning efficiency and light interception efficiency of crop plants (Long et al., 2006; Murchie et al., 2009; Zhu et al., 2010). Increased partitioning efficiency has been accomplished through the release of semi-dwarf cultivars producing higher numbers of seeds per plant and an increase in HI. The new wheat varieties associated with the "green revolution" and introduced in the 20th century were generally shorter and exhibited an increased grain yield at the expense of straw biomass, that is, exhibited enhanced HI. The gai mutant alleles that control this shorter phenotype and increased HI encode mutant forms of the gibberellin response transcription factor, GAI (Peng et al., 1999). Increased light interception efficiency is a consequence of increased leaf area index associated with the development of the semi-dwarf cultivars with improved lodging resistance against the adverse weather conditions, such as rain, wind, and hail (Peng et al., 1999; Long et al., 2006; Murchie et al., 2009). Recently, it was reported that the rice cytokinin GATA transcription factor 1 encoded by Cgal governs a dwarf phenotype as well as chloroplast development in rice (Hudson et al., 2013). Thus, altered Cgal expression appears to mimic the effects of altered gene expression in GA signaling associated with the elite "green revolution" wheat varieties.

Presently, we summarize experimental evidence that targeting the dwarf phenotype, and enhanced photosynthetic performance typically associated with the cold acclimated (CA) state of winter cereals and Brassica napus may represent a novel approach to improve crop yield and productivity. We show that the requirement for cold acclimation to enhance photosynthetic performance can be circumvented by overexpression of the Crepeat/dehydration responsive family of transcription factors. We suggest that this approach may provide important insights into potential molecular approaches focused on at least the maintenance or, perhaps, even the enhancement of plant productivity under sub-optimal growth conditions predicted to be associated with future climate change.

\section{COLD ACCLIMATION INCREASES PHOTOSYNTHETIC PERFORMANCE}

Previous studies have reported that CA winter cultivars of rye (Figure 1A), wheat, barley, Brassica, spinach, and Arabidopsis thaliana are characterized by an increased photosynthetic capacity relative to non-acclimated (NA) controls. Furthermore, the temperature response curves for both $\mathrm{CO}_{2}$ assimilation (Figure 1B) and photosynthetic electron transport (ETR) (Figure 1C) indicate that CA plants exhibit higher rates at all temperatures between 5 and $25^{\circ} \mathrm{C}$ relative to NA controls (Figures 1B,C) (Hüner et al., 1998; Öquist and Hüner, 2003; Dahal et al., 2012a,b). This has been accounted for by the upregulation of carbon metabolism as a consequence of increased gene expression and activities of $\mathrm{CO}_{2}$-fixing enzyme, Rubisco (Hurry and Hüner, 1991; Hurry et al., 1994, 1995, 2000; Hüner et al., 1998; Strand et al., 1999; Öquist and Hüner, 2003; Dahal et al., 2012a,b) as well as enhanced activities of the cytosolic, sucrose biosynthetic enzymes, cFBPase, and SPS (Hurry et al., 1995a; Strand et al., 1999; Savitch et al., 2000a; Rapacz et al., 2008; Dahal et al., 2012a,b) in response to low growth temperature. In addition, winter cultivars of wheat (Savitch et al., 2000a; Leonardos et al., 2003) and Arabidopsis thaliana (Stitt and Hurry, 2002) combine an enhanced sink capacity with increased rates of sucrose export in response to cold acclimation. The major portion of this sucrose is stored as fructans in the crown tissue and leaf mesophyll cell vacuoles during cold acclimation of winter cereals (Pollock and Cairns, 1991; Savitch et al., 2000a). Consequently, cold acclimation of winter wheat, winter rape (Hurry et al., 1995a), and Arabidopsis thaliana (Stitt and Hurry, 2002) results in enhanced $P_{i}$ cycling and increased capacity for RuBP regeneration. Concomitantly, cold acclimation of winter cereals suppresses photorespiration (Savitch et al., 2000b) and stimulates carbon export rates from source leaves (Leonardos et al., 2003). Consequently, the process of cold acclimation of winter cereals appears to co-ordinate system-wide readjustments in plant metabolism in feed-forward stimulation of photosynthetic $\mathrm{CO}_{2}$ fixation due to enhanced source-sink activities and increased capacity for carbon translocation (Hurry et al., 1995a; Strand et al., 1999; Stitt and Hurry, 2002; Leonardos et al., 2003). This is supported by a detailed, comparative metabolomics study of CA vs. NA Arabidopsis thaliana (Gray and Heath, 2005).

These adjustments at the physiological, biochemical, and molecular levels in response to cold acclimation are associated with coordinated changes in leaf anatomy and plant phenotype (Hüner, 1985; Gray et al., 1996, 1997; Strand et al., 1999; Dahal et al., 2012a,b) and induction of freezing tolerance in cold-tolerant species (Sarhan et al., 1997; Pocock et al., 2001; Thomashow, 2001; Savitch et al., 2005; Rapacz et al., 2008; Theocharis et al., 2012). With respect to phenotypic plasticity, 


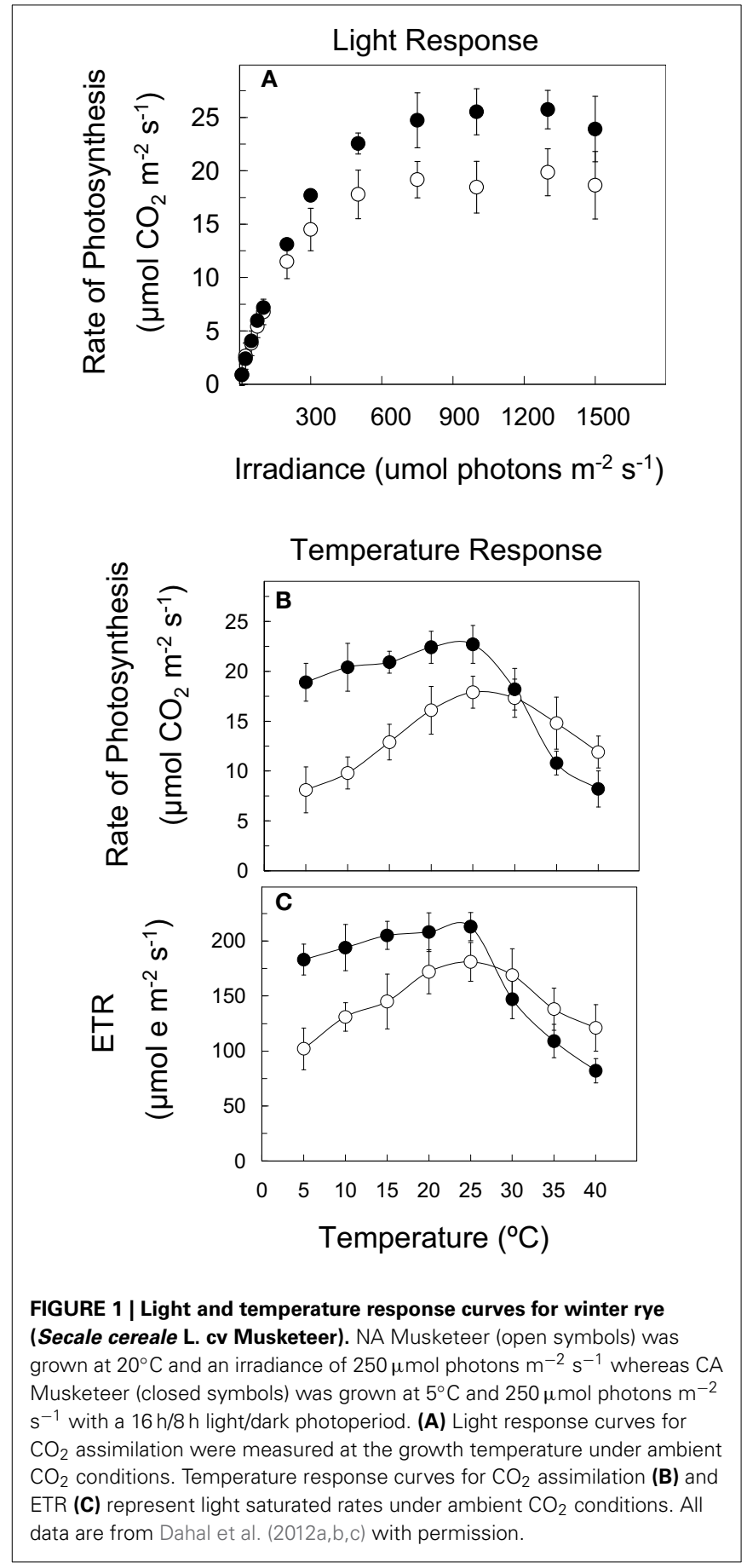

cold acclimation of winter rye, winter wheat, and Brassica napus (Figure 2) as well as spinach and Arabidopsis thaliana generally results in a compact, dwarf phenotype (Hüner, 1985; Boese and Hüner, 1990; Strand et al., 1999; Savitch et al., 2005; Gorsuch et al., 2010a,b; Dahal et al., 2012a,b).

Previously, it has been assumed that the induction of the dwarf phenotype in overwintering herbaceous plants is regulated by low temperature (Levitt, 1980). However, we have shown that this is not the case. In fact, the phenotypic plasticity associated with cold acclimation of winter cultivars is regulated by the redox state of

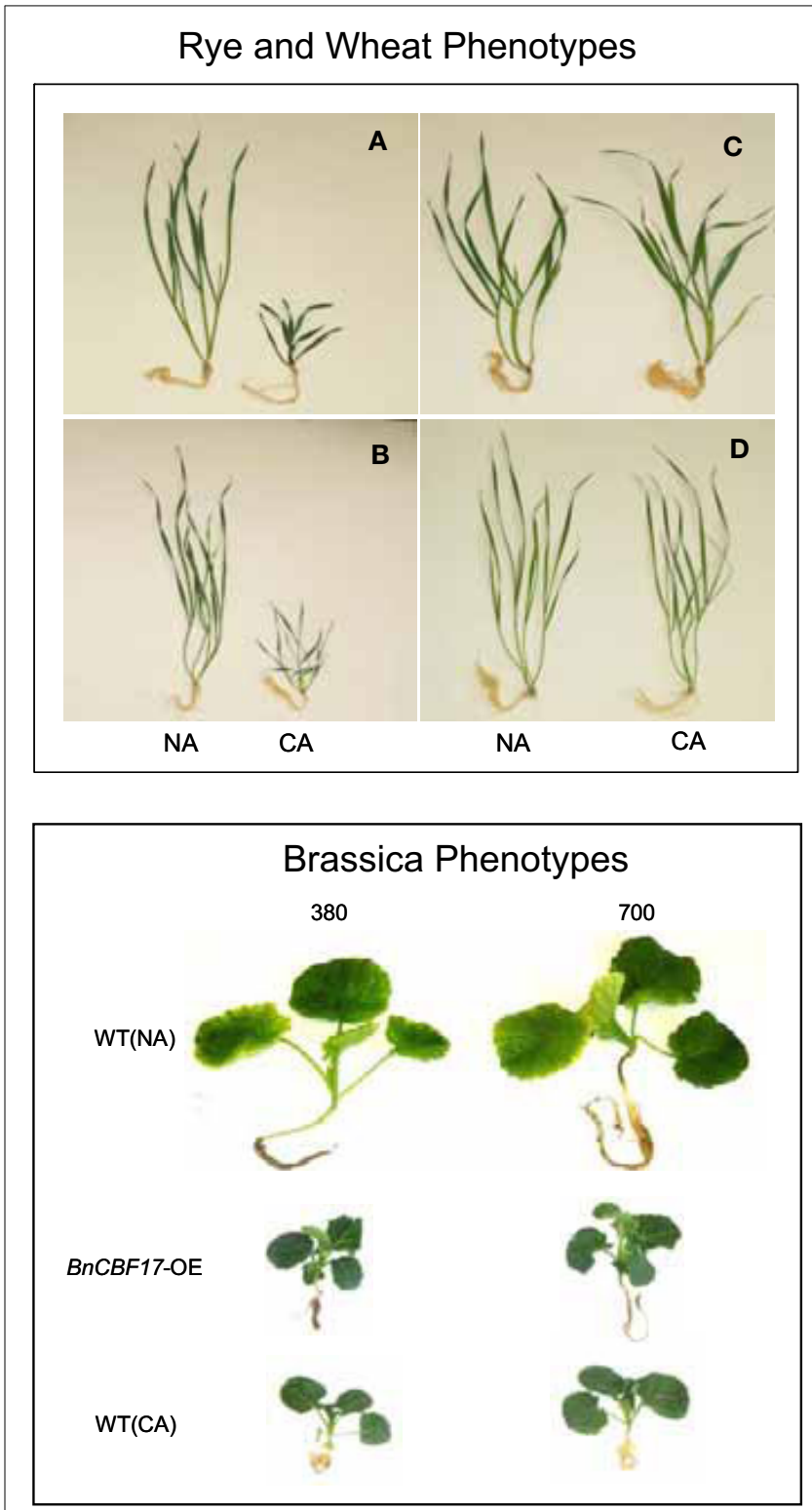

FIGURE 2 | The effect of cold acclimation on plant phenotype. All plants were photographed at similar physiological states based on comparative growth kinetics. See Dahal et al. (2012a,b,c), for details. (A) NA and CA winter rye (Secale cereale L. cv Musketeer). (B) NA and CA Norstar winter wheat (Triticum aestivum L. cv Norstar). (C) NA and CA spring rye (Secale cereale L. cv SR4A). (D) NA and CA spring wheat (Triticum aestivum L. cv Katepwa). NA Brassica napus L. cv Westar WT and the BnCBF17 overexpressor (BnCBF17-OE) were grown at $20^{\circ} \mathrm{C}$ and an irradiance of $250 \mu \mathrm{mol}$ photons $\mathrm{m}^{-2} \mathrm{~s}^{-1}$ with a $16 \mathrm{~h} / 8 \mathrm{~h}$ light/dark photoperiod at either ambient $\left(380 \mathrm{ppm} \mathrm{CO}\right.$ ) or elevated $\mathrm{CO}_{2}\left(700 \mathrm{ppm} \mathrm{CO}_{2}\right.$ ). CA Brassica napus L. Cv Westar WT was grown at $5^{\circ} \mathrm{C}$ and an irradiance of $250 \mu \mathrm{mol}$ photons $\mathrm{m}^{-2} \mathrm{~s}^{-1}$ with a $16 \mathrm{~h} / 8 \mathrm{~h}$ light/dark photoperiod at either ambient (380 ppm $\mathrm{CO}_{2}$ ) or elevated $\mathrm{CO}_{2}(700 \mathrm{ppm} \mathrm{CO}$ ). Photographs are taken from Dahal et al. (2012a,b) with permission.

the chloroplast measured as excitation pressure (Gray et al., 1997; Hüner et al., 1998, 2012, 2013; Wilson et al., 2006; Kurepin et al., 2013). In addition, WCS19, a nuclear encoded gene originally associated with wheat freezing tolerance, has also been reported 
to be regulated by excitation pressure rather than by low temperature (Gray et al., 1997; NDong et al., 2001). Excitation pressure, estimated in vivo using Chl a fluorescence induction (Dietz et al., 1985; Hüner et al., 1998), is a quantitative measure of the proportion of closed PSII reaction centers due to an imbalance between energy absorbed vs. energy either utilized through metabolism and growth or dissipated as heat. Excitation pressure represents a chloroplast redox signal which emanates from the photosynthetic ETR chain and regulates not only the organization and composition of the photosynthetic apparatus but also phenotypic plasticity (Anderson et al., 1995; Hüner et al., 1998, 2003, 2012, 2013; Ensminger et al., 2006; Rosso et al., 2009; Kurepin et al., 2013).

The CA dwarf phenotype is also associated with altered leaf mesophyll cell ultrastructure and increased leaf thickness. The former is characterized by an increase in cytoplasmic volume combined with a decrease in vacuolar volume as estimated from cross sectional areas of transmission electron micrographs which are correlated with increased specific leaf weight relative to NA winter rye and Arabidopsis thaliana (Hüner et al., 1984; Strand et al., 1999). The latter can be accounted for by either increases in leaf mesophyll cell size (Hüner, 1985; Gorsuch et al., 2010a,b) or increases in palisade mesophyll layers (Boese and Hüner, 1990, 1992; Dahal et al., 2012a). These changes in leaf morphology are accompanied by an increase in the leaf protein content (Table 1) as well as an increase in the contents of sucrose and other structural carbohydrates (Guy et al., 1992; Hurry et al., 1995b; Strand et al., 1999, 2003; Savitch et al., 2000a,b; Gorsuch et al., 2010b). Consequently, the absolute shoot biomasses of the CA dwarf plants are comparable to the shoot biomasses of the NA plants with the larger, extended phenotype (Table 1). This indicates a significant increase in total energy per unit plant volume during the autumn cold acclimation period which is critical for winter survival and enhanced seed yield the following spring (Dahal et al., 2012b). Furthermore, the increased photosynthetic capacity exhibited by CA plants is, in part, due to the increased photosynthetic apparatus per unit leaf area (Dahal et al., 2012b). Functionally, this leads to an increased capacity to utilize absorbed light energy which keeps a greater proportion of PSII reaction centers open, that is, lowers excitation pressure (Hüner et al., 2003). This, in turn, results in a lower probability for lightdependent inhibition of photosynthesis due to photoinhibition (Krause, 1994, 1988; Osmond, 1994; Melis, 1999; Murata et al., 2007) under suboptimal growth conditions (Hurry and Hüner, 1992; Hüner et al., 1993; Gray et al., 1996, 1997). Although the coordination of such system-wide adjustments in photosynthesis, carbon metabolism, translocation, and phenotype appear to be correlated with the modulation of chloroplast excitation pressure, the precise molecular mechanism(s) that govern such complex, system-wide changes have yet to be elucidated. This remains a major challenge for future research.

However, the ability to co-ordinate system-wide adjustments in photosynthetic performance in response to low growth temperature appears to be cultivar dependent. In contrast to winter cereals, spring cultivars do not exhibit this change in phenotype but rather maintain an elongated phenotype upon cold acclimation (Figure 2) with minimal changes in SLW and leaf protein content (Table 1) even though spring varieties are able to grow at low temperature (Dahal et al., 2012b, 2013b). Most likely this is due to the differential vernalization requirements for winter vs. spring varieties (Sung and Amasino, 2005; Oliver et al., 2009; Ko et al., 2010; Trevaskis, 2010). However, CA spring cereals exhibit a significant inhibition in photosynthetic capacity coupled with a much higher susceptibility to photoinhibition compared to CA winter cereals (Hurry and Hüner, 1991; Pocock et al., 2001; Dahal et al., 2012b).

\section{COLD ACCLIMATION MINIMIZES DEPENDENCE ON NPO FOR PHOTOPROTECTION}

It is estimated that under optimal growth conditions only about $4.6 \%$ of the initial energy that impinges the leaf surface is conserved as fixed carbon and plant biomass (Zhu et al., 2010;

Table 1 | Effects of cold acclimation on growth and photosynthesis.

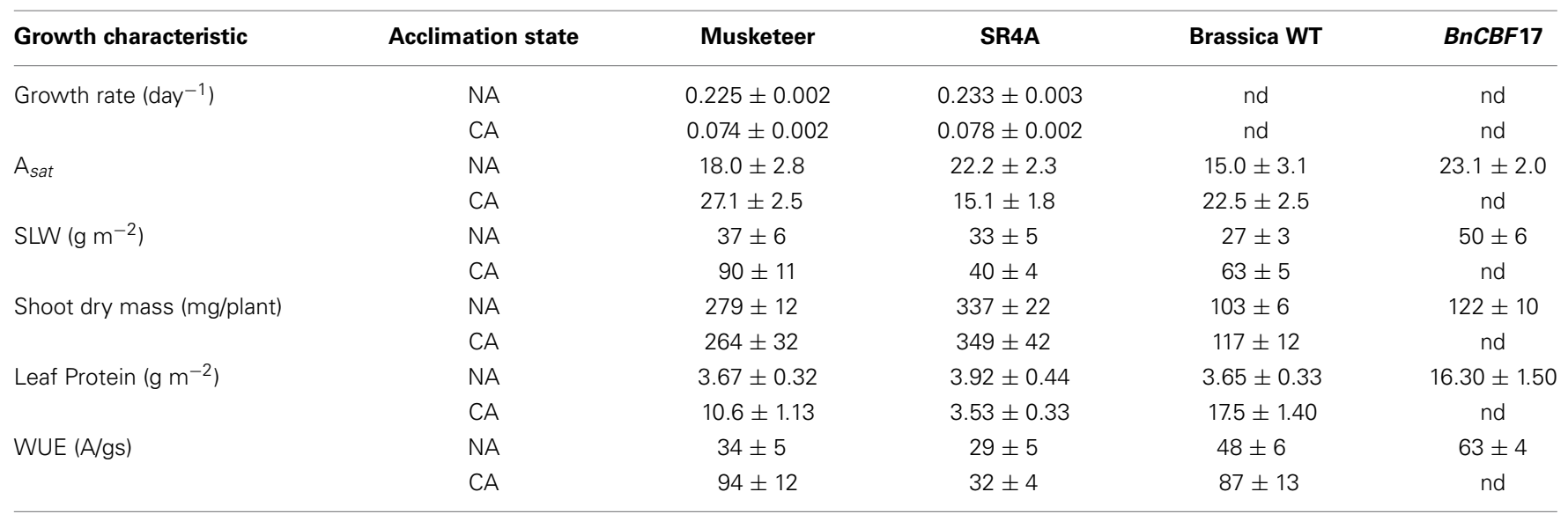

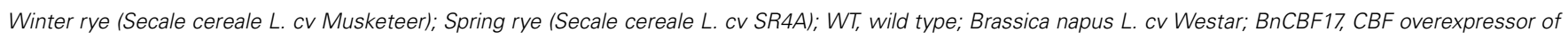

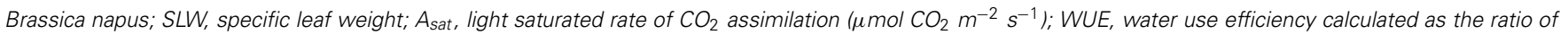
light-saturated rates of $\mathrm{CO}_{2}$ assimilation (A) and stomatal conductance (gs). All data are from Dahal et al. (2012b, 2013b). 
Dahal et al., 2013a). A major challenge in photosynthesis research remains the enhancement in the conversion of absorbed light energy into plant biomass (Murchie et al., 2009; Zhu et al., 2010). Much recent research addressing this issue has focused primarily on targeted genetic approaches either to alter the structure and composition of the photosynthetic photosystems and their associated antenna complexes, to alter the structure of the $\mathrm{CO}_{2}$ fixing enzyme, Rubisco, in order to reduce the rates of photorespiration in C3 crop plants (Spreitzer and Salvucci, 2002; Long et al., 2006; Zhu et al., 2010) or to increase the potential for $\mathrm{C} 4$ photosynthesis in $\mathrm{C} 3$ plants such as rice (Edwards et al., 2008). In contrast to these targeted approaches, we propose that exploitation of the system-wide adjustments in photosynthetic performance orchestrated by cold acclimation provides a novel approach to enhance plant biomass production by co-ordinating source-sink demand which concomitantly minimizes energy loss through NPQ. To assess relative dependence on NPQ, one may compare the balance between the efficiency for light utilization for $\mathrm{CO}_{2}$ assimilation with the efficiency for energy dissipation through NPQ (Dahal et al., 2012a). The former can be measured as the apparent number of photons required to close $50 \%$ of PSII reaction centers (Figure 3), and the latter as the apparent number of photons required to induce one unit of NPQ (Dahal et al., 2012a). An increased capacity for the utilization of photosynthetic reductants to assimilate $\mathrm{CO}_{2}$, will be reflected in an increase in the quantum requirement, that is, a decrease in the initial slope of the light response curve for excitation pressure. For example, Figure 4C (open symbols) illustrates that CA Brassica napus WT exhibits a lower initial slope than that observed for NA Brassica napus WT (Figure 4A, open symbols). This indicates that cold acclimation increases the number photons required to close a PSII reaction centers by 30-50\% compared to NA Brassica. Concomitantly, this is associated with a $30-50 \%$ increase in the number of photons required to induce photoprotection through NPQ in CA (Figure 4F) vs. NA Brassica napus WT (Figure 4D). Thus, CA Brassica napus exhibits a lower dependence on NPQ for photoprotection than NA Brassica napus due to increased rates of photosynthetic ETR and photosynthetic $\mathrm{CO}_{2}$ assimilation (Dahal et al., 2012a). Similar results have been reported for CA vs. NA winter rye and winter wheat which translates into a $60 \%$ increase in seed yield per plant (Dahal et al., 2013b). Thus, cold acclimation of winter rye, winter wheat, and Brassica napus establishes a new homeostatic state which is characterized by an increased photosynthetic capacity for $\mathrm{CO}_{2}$ assimilation and its conversion into biomass or energy per unit plant volume and seed production in wheat under suboptimal growth conditions (Dahal et al., 2013a,b).

In addition to enhanced photosynthetic performance and superior resistance to photoinhibition (Powles, 1984; Long et al., 1994; Edelman and Mattoo, 2008), cold acclimation suppresses stomatal conductance and transpiration rates by $30-40 \%$ regardless of the measuring temperature. The suppression of stomatal conductance observed upon cold acclimation is due, at least in part, to a decrease in leaf stomatal density. (Dahal et al., 2012a,b, 2013b). Consequently, CA plants also exhibit approximately a 3fold increase in leaf water use efficiency (WUE) relative to NA controls (Dahal et al., 2012a,b, 2013b). However, the increase in

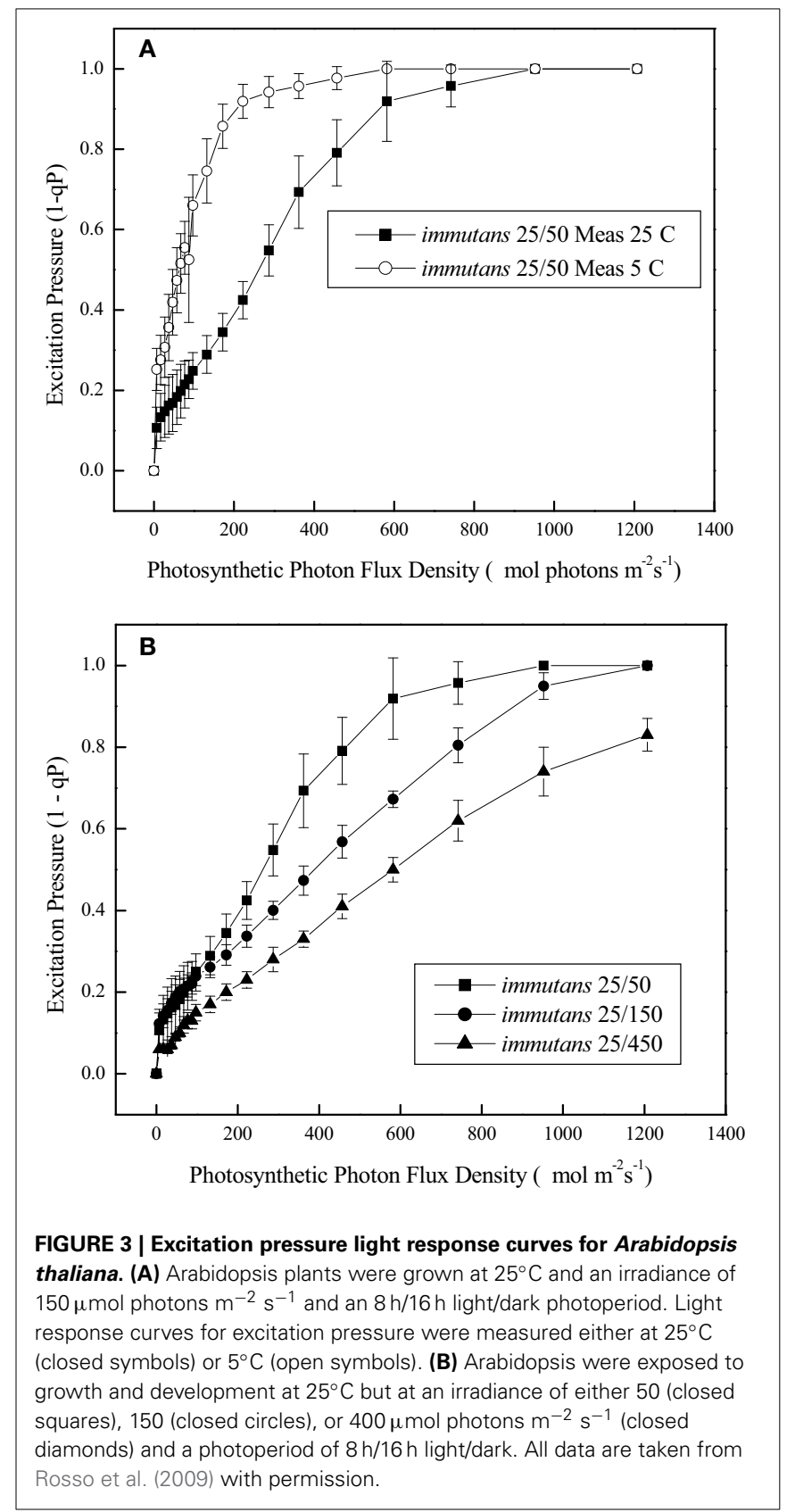

WUE appears primarily due to a combination of a decrease in stomatal density combined with the observed increase in light saturated rates of photosynthesis.

\section{ENHANCED PHOTOSYNTHETIC PERFORMANCE IS MAINTAINED DURING LONG-TERM GROWTH AT ELEVATED $\mathrm{CO}_{2}$}

It has been established that a short-term shift of $\mathrm{C}_{3}$ species from ambient $\left(380 \mu \mathrm{mol} \mathrm{C} \mathrm{mol}{ }^{-1}\right)$ to elevated $\mathrm{CO}_{2}(700 \mu \mathrm{mol}$ $\left.\mathrm{C} \mathrm{mol}{ }^{-1}\right)$ results in an increase in the rates of $\mathrm{CO}_{2}$ assimilation (Long et al., 2004; Ainsworth and Rogers, 2007; Dahal et al., 2012c). This stimulation of photosynthesis in $\mathrm{C}_{3}$ plants due to elevated $\mathrm{CO}_{2}$ occurs because Rubisco is $\mathrm{CO}_{2}$ substrate-limited at 


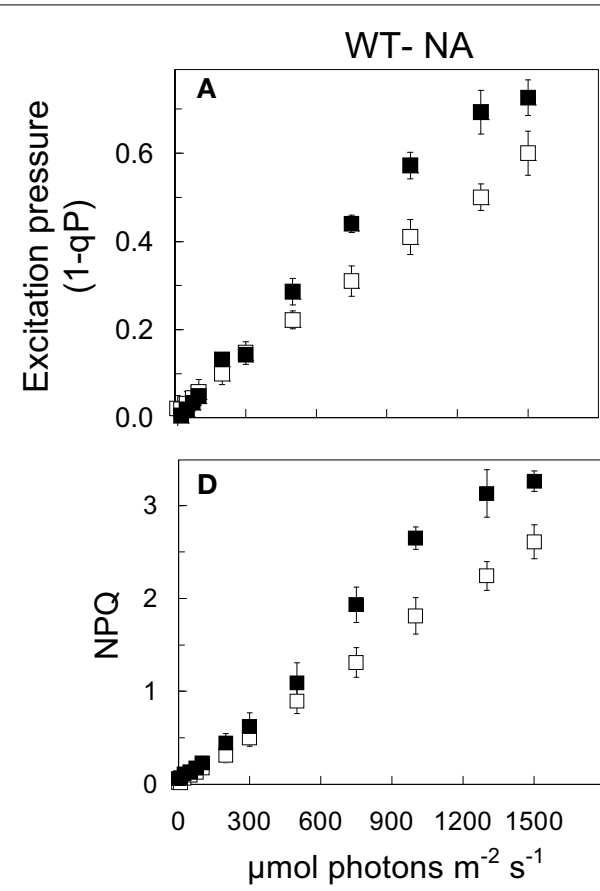

FIGURE 4 | The effects of cold acclimation and $\left[\mathrm{CO}_{2}\right]$ on the light response curves for excitation pressure and NPQ in Brassica napus L. cv Westar. (A,D) NA Westar WT grown at $20^{\circ} \mathrm{C}$ and an irradiance of $250 \mu \mathrm{mol}$ photons $\mathrm{m}^{-2} \mathrm{~s}^{-1}$ with a $16 \mathrm{~h} / 8 \mathrm{~h}$ light/dark photoperiod at either ambient (380 ppm; open symbols) or elevated $\mathrm{CO}_{2}$ (700 ppm $\mathrm{CO}_{2}$; closed symbols). (B,E) BnCBF17 overexpressor (BnCBF17-OE) grown at $20^{\circ} \mathrm{C}$ and an

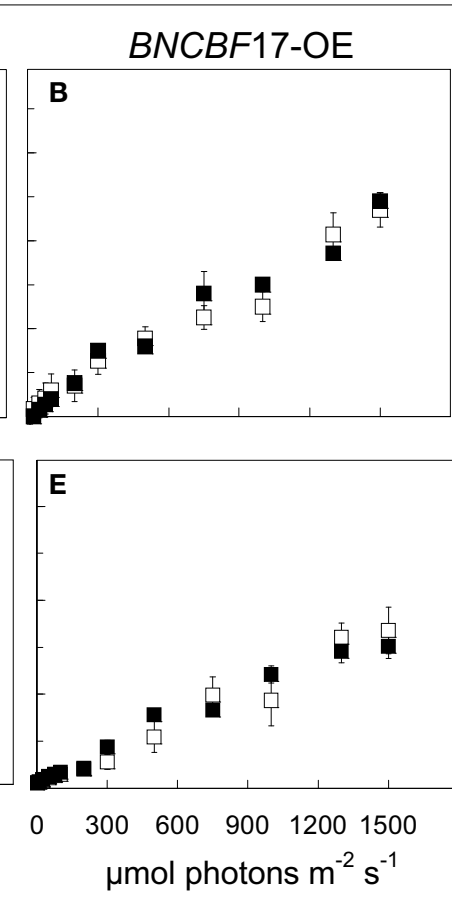

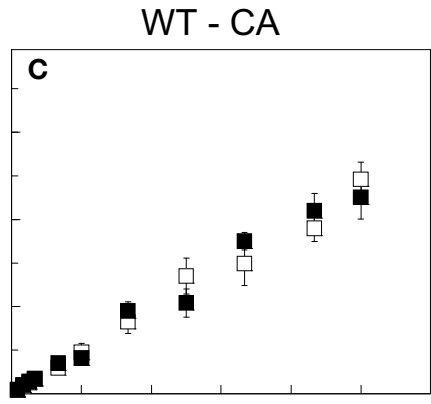

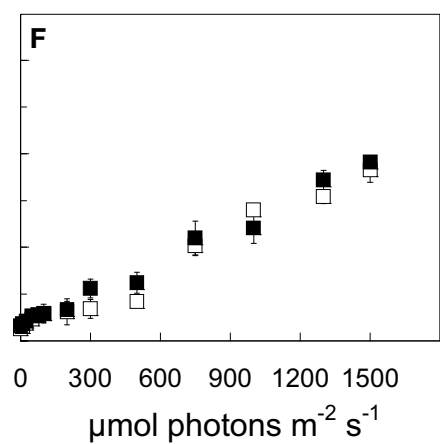

irradiance of $250 \mu \mathrm{mol}$ photons $\mathrm{m}^{-2} \mathrm{~s}^{-1}$ with a $16 \mathrm{~h} / 8 \mathrm{~h}$ light/dark photoperiod at either ambient (380 ppm; open symbols) or elevated $\mathrm{CO}_{2}$ (700 ppm; closed symbols). (C,F) CA Westar WT grown at $5^{\circ} \mathrm{C}$ and an irradiance of $250 \mu \mathrm{mol}$ photons $\mathrm{m}^{-2} \mathrm{~s}^{-1}$ with a $16 \mathrm{~h} / 8 \mathrm{~h}$ light/dark photoperiod at either ambient (380 ppm; open symbols) or elevated $\mathrm{CO}_{2}$ (700 ppm; closed symbols). All data are taken from Dahal et al. (2012a) with permission.

ambient $\mathrm{CO}_{2}$ (Long et al., 2004; Tcherkez et al., 2006) and photorespiration is suppressed since $\mathrm{CO}_{2}$ is a competitive inhibitor of the oxygenation of RuBP by Rubisco (Long et al., 2004).

In contrast to a short-term shift, long-term growth and development of $\mathrm{C} 3$ plants at high $\mathrm{CO}_{2}$ may lead to end product inhibition of photosynthesis due to the accumulation of sucrose in the cytosol (Stitt and Quick, 1989; Foyer et al., 1990). This feedback inhibition of photosynthetic capacity in response to growth and development at elevated $\mathrm{CO}_{2}$ levels may result from the combination of chloroplast Pi-limitations and the down regulation of the expression and activities of key regulatory photosynthetic enzymes (Sharkey and Vanderveer, 1989; Stitt and Quick, 1989; Drake et al., 1997; Long et al., 2004). The results in Figure 5A illustrate the inhibition light saturated rates of $\mathrm{CO}_{2}$ assimilation in WT Brassica napus grown at $25^{\circ} \mathrm{C}$ at either ambient (open symbols) or elevated $\mathrm{CO}_{2}$ (closed symbols). Consequently, WT Brassica napus grown at elevated $\mathrm{CO}_{2}$ exhibits higher excitation pressure under $\mathrm{CO}_{2}$ saturation conditions (Figure 5B, closed symbols) than WT Brassica napus grown at ambient $\mathrm{CO}_{2}$ conditions (Figure 5B, open symbols). However, CA Brassica napus WT does not suffer from feedback limited photosynthesis as a consequence of growth and development at elevated $\mathrm{CO}_{2}$ (Dahal et al., 2012a).

Similar to CA Brassica napus WT, CA winter cereals exhibit a $30-40 \%$ increase in light and $\mathrm{CO}_{2}$-saturated rates of photosynthesis at both ambient and elevated $\mathrm{CO}_{2}$. This was accompanied by a $35-50 \%$ decrease in excitation pressure and non-photochemical energy dissipation. Concomitantly, biomass increased by $28-46 \%$ and grain yield per plant by $60 \%$ (Dahal et al., 2013b). Thus, CA Brassica napus, winter rye, and wheat are able to maintain their superior photosynthetic performance with respect to light and $\mathrm{CO}_{2}$ saturated rates of $\mathrm{CO}_{2}$ assimilation relative to NA controls and do not exhibit feedback inhibition of photosynthesis when exposed to growth and development at elevated $\mathrm{CO}_{2}$. However, since this is not the case for spring rye and spring wheat cultivars, the potential for enhancement of photosynthetic performance and grain yield of cereals during long-term growth at elevated $\mathrm{CO}_{2}$ appears to be cultivar dependent (Dahal et al., 2013b).

Several reports have shown that a previous exposure to one type of abiotic stress can lead to enhanced tolerance to other abiotic and biotic stresses. Cold acclimation of overwintering cereals results in increased systemic resistance to plant infection by psychrophilic fungi (Hiilovaara-Teijo et al., 1999; Griffith and Yaish, 2004). Changes in temperature and $\mathrm{CO}_{2}$ levels affect the interactions between plant and insect pollinators as well as plant and insect herbivores due to alterations in plant phenology (DeLucia et al., 2012). Kane et al. (2013) compared the global gene expression of NA and CA Norstar winter wheat grown at either ambient or elevated $\mathrm{CO}_{2}$ conditions. Global gene expression analyses using microarrays combined with bioinformatics indicated that gene expression in general was more sensitive to elevated $\mathrm{CO}_{2}$ in NA, with 1022 genes in total, in contrast to 372 genes differentially regulated by $\mathrm{CO}_{2}$ in CA Norstar (Kane et al., 


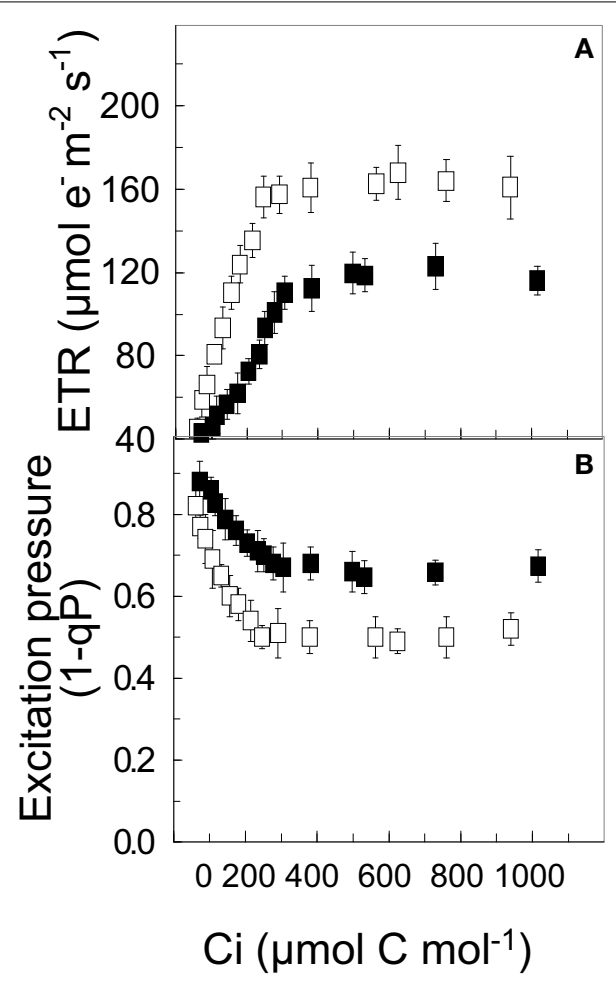

FIGURE 5 | The effects long-term growth $\left[\mathrm{CO}_{2}\right]$ on the $\mathrm{CO}_{2}$ response curves for ETR (A) and excitation pressure (B) for WT Brassica napus $L$. cv Westar. Plants were grown at $20^{\circ} \mathrm{C}$ and an irradiance of $250 \mu \mathrm{mol}$ photons $\mathrm{m}^{-2} \mathrm{~s}^{-1}$ with a $16 \mathrm{~h} / 8 \mathrm{~h}$ light/dark photoperiod at either ambient (380 ppm; open symbols) or elevated $\mathrm{CO}_{2}$ (700 ppm $\mathrm{CO}_{2}$; closed symbols). All data are taken from Dahal et al. (2012a) with permission.

2013). However, the most striking effect of long-term growth at high $\mathrm{CO}_{2}$ was the fact that 121 of the 768 genes down-regulated by growth at elevated $\mathrm{CO}_{2}$ in NA Norstar are either pathogen-related or associated with systemic acquired resistance which demonstrates a major negative impact on pathogen and biotic stress defense mechanisms in NA winter wheat upon growth at high $\mathrm{CO}_{2}$. In contrast, CA Norstar exhibits minimal down regulation of the same genes associated with pathogen resistance and biotic stress defense. In fact, growth of CA Norstar at elevated $\mathrm{CO}_{2}$ caused an induction of genes involved in the biosynthesis of phytoalexins and anthocyanins as well as an up-regulation of chalcone synthase and dihydroflavonol-4-reductase (Kane et al., 2013). In addition, genes involved in photoprotection (ELIPs) and the maintenance of chloroplast stability (chaperonins) were significantly up-regulated during growth and development of CA Norstar at elevated $\mathrm{CO}_{2}$ (Kane et al., 2013). This is consistent with the physiological data which indicate that cold acclimation generally enhances photoprotection and the stability of the photosynthetic apparatus even under elevated $\mathrm{CO}_{2}$ conditions. Thus, based on the global microarray and bioinformatics analyses (Kane et al., 2013), we predict that cold acclimation not only enhances photosynthetic performance, it should also enhance inherent resistance to biotic stress. However, the latter must be confirmed experimentally and is most likely cultivar dependent.

\section{OVEREXPRESSION OF CBFS CIRCUMVENTS THE REOUIREMENT FOR COLD ACCLIMATION}

The expression of CBFs (C-repeat binding factors) initiate the expression of $C O R$ genes necessary to acquire freezing tolerance and induce a dwarf phenotype that is comparable to CA plants (Figure 2) (Jaglo-Ottosen et al., 1998; Medina et al., 1999; Zarka et al., 2003; Benedict et al., 2006; Chinnusamy et al., 2007; Thomashow, 2010; Lee and Thomashow, 2012). However, in addition to mimicking the freezing tolerance response, growth of $C B F$ overexpressors at $25^{\circ} \mathrm{C}$ also mimicks the enhanced photosynthetic capacity (Figures 4B,E), increased plant biomass and WUE (Table 1) typically associated with cold acclimation. This is consistent with the stimulation of the rates of photosynthetic ETR and $\mathrm{CO}_{2}$ assimilation reported for the $B n C B F 17$ overexpressor for Brassica napus (Dahal et al., 2012a). Furthermore, similar to CA Brassica napus WT, the BnCBF17 overexpressor also does not exhibit feedback inhibition of photosynthesis during long-term growth at elevated $\mathrm{CO}_{2}$ (Dahal et al., 2012a). Thus, both cold acclimation and $B n C B F 17$ overexpression overcome the feedback-limited photosynthesis observed in NA control WT Brassica plants. Thus, we conclude that overexpression of $B n C B F 17$ circumvents the requirement for cold acclimation to co-ordinate the system-wide adjustments in plant phenotype, photosynthetic performance and source-sink relationships in Brassica napus. Although CBF overexpression clearly alters the physiology of the shoot, little or no information is available with respect to the impact of $C B F$ overexpression on root morphology, physiology, and nutrient uptake.

CA winter rye not only exhibits significantly higher rates of $\mathrm{CO}_{2}$ assimilation (Figure 1B, closed symbols) and ETR (Figure 1C, closed symbols) but also a lower temperature senstivity at all temperatures between 5 and $25^{\circ} \mathrm{C}$ than NA winter rye (Figure 1, open symbols). Similar trends were observed for NA and CA Brassica napus WT (Dahal et al., 2012b). However, most surprising is the fact that the temperature response curves for $\mathrm{CO}_{2}$ assimilation and photosynthetic ETR for CA Brassica napus are mimicked by simply overexpressing $B n C B F 17$ even when these plants are grown at $25^{\circ} \mathrm{C}$ (Dahal et al., 2012b). To our knowledge, this represents the first report of such a novel manipulation of the temperature sensitivity of photosynthesis.

However, in contrast to overexpression of $B n C B F 17$, overexpression of $B n C B F 5$ resulted in minimal changes in photosynthetic performance Brassica napus (Savitch et al., 2005). Clearly, the enhanced photosynthetic performance induced by $C B F$ overexpression appears to be dependent upon the specific member of this family of transcription factors that is overexpressed. Thus, a more detailed assessment of the effects of overexpression of each member of the $C B F$ family of transcription factors is required.

\section{THE POTENTIAL ROLE OF CBFs}

A major focus of research which attempts to elucidate the molecular mechanisms underlying plant cold acclimation and freezing tolerance has been on changes in cell membrane structure as reflected in changes in membrane lipid and fatty acid content and composition. An inherent assumption is that the plant cell membrane is the primary site that determines the potential of plants to acclimate to low temperature and consequently 
exhibit maximum freezing tolerance (Levitt, 1980; Steponkus, 1984; Guy, 1990; Murata and Los, 1997; Thomashow, 2001; Los and Murata, 2002; Chinnusamy et al., 2007). In cyanobacteria, two-component histidine kinases activated by changes in membrane viscosity have been shown to stimulate the expression of specific fatty acid desaturases. This results in the modulation of membrane fluidity in response to low temperature stress in cyanobacteria (Los and Murata, 2002; Xin, 2002; Los et al., 2013). Low temperature-induced alterations in the physical structure of plant cell membranes also activates $\mathrm{Ca}^{2+}$ channels and rapidly generates a $\mathrm{Ca}^{2+}$ signal (Monroy et al., 1998; Plieth et al., 1999; Orvar et al., 2000). The rapid increase in cytosolic $\mathrm{Ca}^{2+}$ activates a cytosolic protein kinase whose substrate is ICE1. The phosphorylation of ICE1 is required for the induction of a family $C B F$ transcription factors which regulate the expression of $C O R$ genes essential for acquisition of maximal freezing tolerance (Jaglo-Ottosen et al., 1998; Medina et al., 1999; Zarka et al., 2003; Benedict et al., 2006; Chinnusamy et al., 2007; Thomashow, 2010; Lee and Thomashow, 2012). The expression of CBF3 in Arabidopsis thaliana is positively regulated by the constitutively expressed ICE1 gene, the product of which binds to multiple regulatory elements present in the $C B F 3$ promoter and stimulates its transcription (Chinnusamy et al., 2007; Thomashow, 2010). The action of ICE1, in turn, is tightly regulated by SIZ1, a SUMO E3 ligase, and HOS1 which is a RING finger E3 ligase (Lee et al., 2001; Zhu et al., 2004; Dong et al., 2006; Miura et al., 2007; Hua, 2009; Miura and Ohta, 2010; Thomashow, 2010).

Enhanced freezing tolerance has been reported in plants such as A. thaliana, canola (Brassica napus L.), tomato (Solanum lycopersicum L.), and poplar (Populus balsamifera subsp. trichocarpa) in which $C B F$ s have been over-expressed (Jaglo-Ottosen et al., 1998; Hsieh et al., 2002; Savitch et al., 2005; Benedict et al., 2006). In herbaceous plants, $C B F$ overexpression is typically associated with the dwarf phenotype observed during cold acclimation even though the plant has been grown at warm temperatures (Hsieh et al., 2002; Savitch et al., 2005; Achard et al., 2008; Huang et al., 2009; Dahal et al., 2013a). Thus, the CBF regulon not only regulates freezing tolerance but also has dramatic affects on plant development that are considered to be controlled by the family of plant phytochromes as well as phytohormones (Franklin, 2009; Kurepin et al., 2013).

All photoautotrophic organisms sense changes in light quality as a "biogenic signal" through photoreceptors such as the phytochromes and cryptochromes to regulate photomorphogenesis (Pogson et al., 2008; Sakamoto et al., 2008; Waters and Langdale, 2009; Jarvis and Lopez-Juez, 2013). However, photoautotrophs also sense changes in light intensity as fluctuations in energy input for photosynthesis as an "operational signal" to maintain a cellular energy balance that is, photostasis (Hüner et al., 2003, 2012; Pogson et al., 2008). Photoautotrophs must balance the extremely fast rates of cellular energy input through the temperature-insensitive photochemical reactions of photosystem I and photosystem II with the slower, and temperature-dependent enzyme processes involved in either energy dissipation as heat or energy utilization through primary $\mathrm{C}, \mathrm{N}$, and $\mathrm{S}$ assimilation (Foyer et al., 2000; Foyer and Noctor, 2002; Murchie et al., 2009; Hüner and Grodzinski, 2011; Hüner et al., 2012, 2013). The regulation of the phytochrome-dependent, photomorphogenic signal transduction pathways (Franklin and Whitelam, 2007; Pogson et al., 2008; Franklin, 2009) as well as the retrograde sensing/signaling pathways between the chloroplast and the nucleus (Koussevitzky et al., 2000; Nott et al., 2006; Lim et al., 2007; Fernandez and Strand, 2008; Pogson et al., 2008; Woodson and Chory, 2008) involved in remodeling of the photosynthetic apparatus are both light- and temperature-dependent (Li et al., 1993; Franklin, 2009; Kim and Apel, 2013; Hüner et al., 2012, 2013). Thus, cross-talk between the biogenic signaling pathways and the complex operational signaling networks must exist since both govern plant plasticity in response to an ever-changing environment. Elucidation of nature of this complex integration of light sensing/signaling networks remains a major challenge for future research.

Recently, we proposed that CBFs act as master regulators of cold acclimation and photosynthetic performance which integrate both the upstream and downstream signals (Kurepin et al., 2013). In our model illustrated in Figure 6, we propose that redox input signals from chloroplasts (green), manifested as modulation of excitation pressure, are transduced to the nucleus (red) via retrograde regulation and stimulate $C B F$ expression. Recently, we reported that $C B F 3$ in Arabidopsis thaliana is regulated by excitation pressure rather than low temperature per se (Bode, 2012; Kurepin et al., 2013). Furthermore, we suggest that the phenotype and physiological properties of CA plants occurs by the stimulation of $C B F$ gene expression to induce not only freezing tolerance but also genes associated with photosynthesis, cytosolic carbon metabolism and respiration in addition to the activation of GA2ox genes which decreases the levels of growth-active GAs. Growth-active GAs normally bind to DELLA proteins to de-repress genes involved in cell growth and stem elongation (Peng and Harberd, 1997; Peng et al., 1997, 1999). Thus, accumulation of growth-inactive GAs maintains levels of DELLA proteins such growth and stem elongation are repressed which generates a dwarf phenotype. This dwarf phenotype exhibits enhanced photosynthetic performance and increased dry biomass per unit plant volume (Savitch et al., 2005; Dahal et al., 2012a, 2013a,b) coupled with enhanced seed yield in CA wheat (Dahal et al., 2013b). We conclude that plants sense low temperature through a complex sensing/signaling network which integrates changes in temperature and actinic light intensity through modulation of operational signals emanating from the chloroplast due to chloroplast redox imbalance or excitation pressure (Hüner et al., 1998; Ensminger et al., 2006; Hüner et al., 2012, 2013; Kurepin et al., 2013). Thus, the chloroplast should not only be considered the primary energy in transformer but also a major cellular energy sensor for detecting changes in the environment (Hüner et al., 1998; Pfannschmidt, 2003; Murchie et al., 2009). However, operational chloroplast redox signaling must be integrated with regulation associated changes in light quality sensed through photoreceptors such as phytochrome (Franklin and Whitelam, 2007; Franklin, 2009) as well as through specific cell membrane, low temperature sensors (Murata and Los, 1997; Plieth et al., 1999; Knight and Knight, 2000; Los and Murata, 2002; Los et al., 2013) in order to establish a new CA, homeostatic state. 


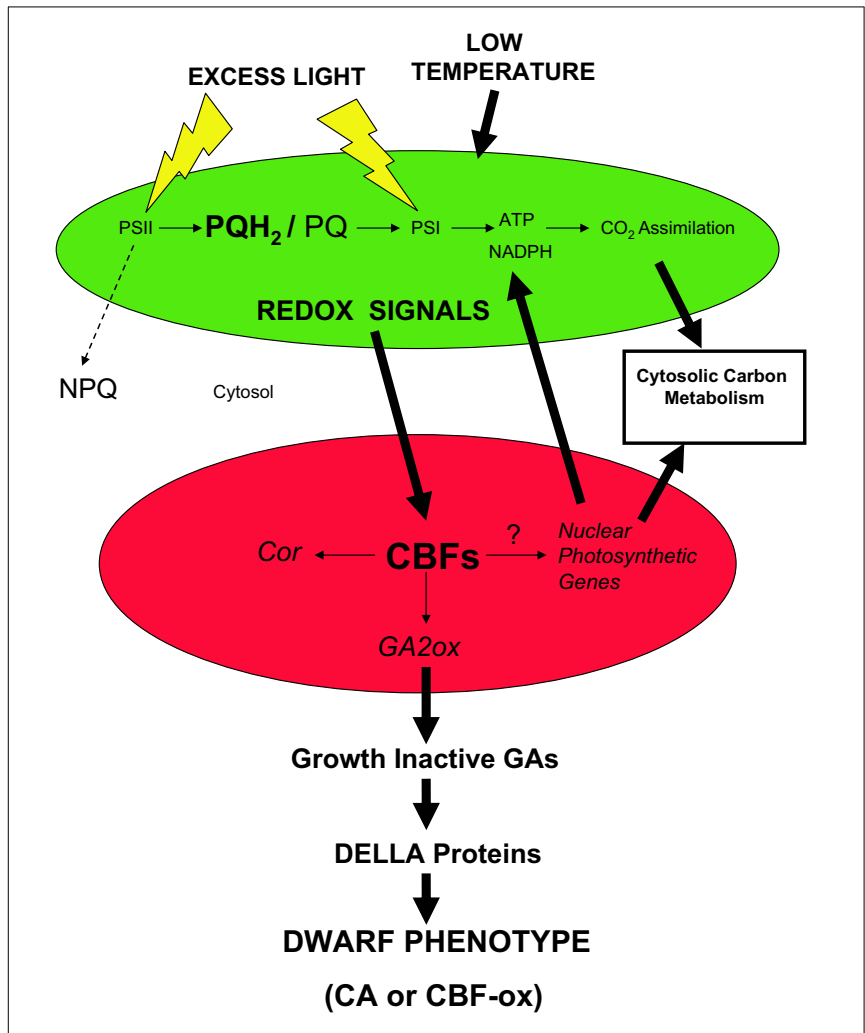

FIGURE 6 | A proposed model illustrating the role of CBFs in governing the system-wide integration of excitation pressure, photosynthetic capacity and the dwarf phenotype. Growth of plants either under excess light or low temperature poises the intersystem photosynthetic electron transport chain of the chloroplast (green) in a reduced state as indicated by the accumulation of plastoquinol $\left(\mathrm{POH}_{2}\right)$ relative to plastoquinone $(\mathrm{PQ})$. This is due to an imbalance between the flux of energy absorbed through extremely fast, temperature-independent photochemistry occurring within the PSII and PSI reaction centers relative to the energy utilized either through much slower, temperature-sensitive biochemical reactions involved in $\mathrm{CO}_{2}$ assimilation, cytosolic carbon metabolism, and export or the energy dissipated as heat through NPQ. Such an energy imbalance increases excitation pressure. Through retrograde signaling pathways, the myriad redox signals generated by the chloroplast due to the increased excitation pressure are transduced to the nucleus (red) to modulate CBF expression. This leads to the activation not only of $C O R$ genes important in freezing tolerance but also the activation of nuclear encoded photosynthetic genes associated with thylakoid membrane protein complexes involved in photosynthetic electron transport as well as enzymes of the Calvin-Benson Cycle and cytosolic sucrose biosynthesis. The latter results in the increased capacity for $\mathrm{CO}_{2}$ assimilation upon growth under high excitation pressure. DELLA proteins are repressors of stem elongation. Growth-active GAs stimulate stem elongation by activating the breakdown of DELLA proteins, and thus, de-repressing stem elongation. CBFs affect the biosynthetic pathways for GA biosynthesis by activating nuclear encoded GA20x genes which predisposes plants to accumulate growth-inactive GAs (Kurepin et al., 2013). Consequently, activation of CBFs by excitation pressure results in the accumulation of growth inactive GAs which maintains the plant in a repressed growth state due to the accumulation of DELLA proteins. As illustrated in the model, the low growth temperature or high light requirement usually needed to elicit enhanced photosynthetic capacity and the dwarf phenotype can be circumvented by overexpression over-expression of $C B F S$ (CBF-OX). The enhanced photosynthetic capacity induced either by excitation pressure or overexpression of $\mathrm{CBFs}$, minimizes the requirement for photoprotection of the chloroplast through NPQ as illustrated by the broken arrow. The mechanism by which CBFs activate the expression of known nuclear photosynthetic genes is presently unknown.

\section{CBFs, CLIMATE CHANGE, AND CROP PRODUCTIVITY}

The intergovernmental panel on climate change has predicted that the atmospheric $\mathrm{CO}_{2}$ concentration will double from present $380 \mu \mathrm{mol} \mathrm{C} \mathrm{mol}^{-1}$ to ca. $700 \mu \mathrm{mol} \mathrm{C} \mathrm{mol}{ }^{-1}$ by the end of the twenty-first century which may be coupled to an increase in average global temperature (IPCC, 2007). The predicted increase in atmospheric $\mathrm{CO}_{2}$ and drastic temperature changes associated with global climate change may increase the severity of water stress as well as the incidence of biotic stresses (Hatfield et al., 2011; DeLucia et al., 2012; Vandegeer et al., 2012). Such sub-optimal growth conditions due to climate change may substantially affect the photosynthetic performance of plants and hence, plant biomass production and crop seed yield. To add to the complexity of the effects of climate change on crop productivity, the sub-optimal growth conditions associated with climate change is occurring at a time when the world population is likely to increase by about $30 \%$ by 2050 (UN Report, 2011). It has been predicted that the world food demand will double in the next 20 years due to increased world population as well as increased per capita food consumption (Murchie et al., 2009). This has triggered an immediate need to substantially enhance seed yield and productivity of major food crops such as rice, wheat, and maize to meet the nutritional demand of the increasing population. This urgent need is exacerbated by the fact that the projected increased food demand is occurring at a time when continued losses of prime agricultural land is occurring due to urbanization, desertification in most of the developing countries, an increasing proportion of grain is being diverted for animal feed and biofuel generation which are combined with the suboptimal growth conditions for crop production due to climate change (Murchie et al., 2009; Zhu et al., 2010).

During the 1960s and 1970s wheat yields worldwide increased significantly due to the development of new varieties and increased availability and use of $\mathrm{N}$ fertilizers. This led to the "green revolution" which was characterized by short, sturdy, semi-dwarf genotypes that exhibit an increased $\mathrm{HI}$ and a decreased tendency to lodge (Peng et al., 1999). Subsequent molecular and genetic analyses of these semi-dwarf varieties showed that this phenotype was conferred by dominant mutant dwarfing alleles which are orthologs of the Gibberellic Acid Insensitive gene (GAI) of Arabidopsis thaliana (Peng et al., 1999). In wild type, GAI represses stem elongation at low endogenous GA levels but under high endogenous of GA levels, GA binds to GAI and de-represses the inhibitory effect of GAI which results in normal stem elongation and an elongated phenotype (Peng et al., 1997, 1999; Peng and Harberd, 1997). In the dwarf plants, the mutant gene, gai, is present which does not bind endogenous GA. Consequently, mutants retain a dwarf phenotype irrespective of endogenous GA levels.

Since growth active GAs stimulate stem elongation (Hopkins and Hüner, 2008), application of exogenous GAs to CBFoverexpressing plants rescues the dwarf phenotype. In contrast, application of other plant hormones known to affect shoot growth does not rescue the dwarf phenotype (Hsieh et al., 2002; Achard et al., 2008). Published reports indicate that overexpression of CBFs results in increased levels of DELLA proteins (Achard et al., 2008; Kurepin et al., 2013) which repress stem 
elongation and leads to a dwarf phenotype (Peng and Harberd, 1997; Peng et al., 1997). Recent evidence indicates that excitation pressure not only regulates the expression of photosynthetic genes (Hüner et al., 1998; Rosso et al., 2009) but also activates AtCBF3 expression in Arabidopsis thaliana (Bode, 2012; Kurepin et al., 2013). Since growth- active GAs stimulate the degradation of DELLA proteins (Achard et al., 2008), the accumulation of DELLA proteins, in part, reflect the increased expression of GA2ox genes which leads to the accumulation of growth-inactive GAs (Kurepin et al., 2013). Thus, the published evidence is consistent with the notion that excitation pressure governs the dwarf phenotype through the activation $C B F$ gene expression which, in turn, may control the expression of GA2ox genes which consequently reduces the accumulation of growth active GAs in CA plants as well as plants grown under excessive irradiance (Gray et al., 1997; Achard et al., 2008; Kurepin et al., 2013). Consequently, plants grown under either excessive irradiance or low temperature exhibit a dwarf phenotype which is mimicked by overexpression of CBFs (Gilmour et al., 2000; Savitch et al., 2005; Dahal et al., 2012a) (Figure 6).

The model illustrated in Figure 6 is consistent with the thesis that photosynthesis and the chloroplast have a dual role-not only do they represent the major energy transformers of sunlight into biomass, they also govern a broad range of physiological and plant developmental processes which have a direct impact on phenotypic plasticity. This model is consistent with the "grand design of photosynthesis" first proposed by Arnon (1982) and subsequently supported by a series of reviews in the last 20 years focused on photoacclimation (Anderson et al., 1995), acclimation to low temperature and light (Hüner et al., 1998; Pfannschmidt, 2003), acclimation and cell death (Mullineaux and Baker, 2010) as well as plant growth and productivity (Murchie et al., 2009; Kurepin et al., 2013).

The maintenance of crop yield stability through enhanced tolerance to environmental stresses such as drought, low and high temperature, as well as biotic stress associated with global climate change remains a crucial challenge to maximize future crop productivity worldwide (Powell et al., 2012). We suggest that targeting the $C B F$ family of transcription factors in major crop species may be a novel approach to improve crop productivity through increased photosynthetic performance coupled with increased WUE and the potential for enhanced resistance to biotic stress. However, an important caveat to this approach is that low temperature induction of CBFs in Arabidopsis thaliana also activates the expression of Flowering Locus $\mathrm{C}(F L C)$, a negative regulator of flowering (Seo et al., 2009). This results in a significant delay in flowering time which reflects an evolutionary mechanism to prevent premature floral development during the late fall or early spring seasons. Similarly, overexpression of AtCBF3 delayed the onset of bolting by 4 to 9 days at $20^{\circ} \mathrm{C}$ in Arabidopsis (Gilmour et al., 2000). Such a delay in flowering time has been confirmed in subsequent studies (Magome et al., 2004; Seo et al., 2009). Furthermore, seed yield also appears to be reduced in $\mathrm{CBF}$ overexpressors compared to wild type when grown at warm temperatures (Liu et al., 1998; Gilmour et al., 2000). Thus, when grown under optimal conditions, the increased photosynthetic performance induced by $C B F$ overexpression may not translate into increased seed yield. However, it is crucial to compare the conversion of plant biomass into seed yield in $C B F$ overexpressors with wild type plants when grown under suboptimal growth conditions. The prediction is that the $C B F$ overexpressor should out perform the wild type under such conditions. Further research is required to confirm this prediction.

\section{ACKNOWLEDGMENTS}

The research summarized in this review was supported, in part, by the Natural Sciences and Engineering Research Council of Canada (NSERC) as well as industrial and government partners, through the Green Crop Research Network (GCN). Norman P. A. Hüner and Fathey Sarhan also acknowledge research support through their individual NSERC Discovery Grants. Norman P. A. Hüner is grateful for financial support awarded through the Canada Foundation for Innovation (CFI) and Canada Research Chairs (CRC) programme.

\section{REFERENCES}

Achard, P., Gong, F., Cheminant, S., Alioua, M., Hedden, P. and Genschik, P. (2008). The Cold-inducible CBF1 factor-dependent signaling pathway modulates the accumulation of the growth-repressing Della proteins via its effect on gibberellin metabolism. Plant Cell 20, 2117-2129. doi: 10.1105/tpc.108.058941

Adams III, W. W., and Demmig-Adams, B. (1993). "Energy dissipation and photoprotection in leaves of higher plants," in Photosynthetic Responses to the Environment, Vol. 8, eds H. Y. Yamamoto and C. M. Smith (Rockville, MD: American Society of Plant Physiologists), 27-36.

Ainsworth, E. A., and Rogers, A. (2007). The response of photosynthesis and stomatal conductance to rising [CO2]: mechanisms and environmental interactions. Plant Cell Environ. 30, 258-270. doi: 10.1111/j.1365-3040.2007.01641.x

Anderson, J. M., Chow, W. S. and Park, Y.-I. (1995). The grand design of photosynthesis: acclimation of the photosynthetic apparatus to environmental cues. Photosynth. Res. 46, 129-139. doi: 10.1007/BF00020423

Arnon, D. I. (1982). Sunlight, earth life: the grand design of photosynthesis. Sciences 22, 22-27. doi: 10.1002/j.2326-1951.1982.tb02101.x

Benedict, C., Skinner, J. S., Meng, R., Chang, Y., Bhalero, R., Hüner, N. P. A., et al. (2006). The CBF1-dependent low temperature signalling pathway, regulon and increase in freeze tolerance are conserved in Populus spp. Plant Cell Environ. 29, 1259-1272. doi: 10.1111/j.1365-3040.2006.01505.x

Bode, R. (2012). Effects of Excitation Pressure on Variegation and Global Gene Expression in Arabidopsis thaliana. PhD. Thesis, University of Western Ontario, London, ON, Canada.

Boese, S. R., and Hüner, N. P. A. (1990). Effect of growth temperature and temperature shifts on spinach leaf morphology and photosynthesis. Plant Physiol. 94, 1830-1836. doi: 10.1104/pp.94.4.1830

Boese, S. R., and Hüner, N. P. A. (1992). Developmental history affects the susceptibility of spinach leaves to in vivo low temperature photoinhibition. Plant Physiol. 99, 1141-1145. doi: 10.1104/pp.99.3.1141

Chinnusamy, V., Zhu, J., and Zhu, J. K. (2007). Cold stress regulation of gene expression in plants. Trends Plant Sci. 12, 444-451. doi: 10.1016/j.tplants.2007.07.002

Dahal, K., Gadapati, W., Savitch, L., Singh, J., and Hüner, N. P. A. (2012a). Cold acclimation and $B n C B F 17$-over-expression enhance photosynthetic performance and energy conversion efficiency during long-term growth of Brassica napus under elevated $\mathrm{CO}_{2}$ conditions. Planta 236, 1639-1652. doi: 10.1007/s00425-012-1710-2

Dahal, K., Kane, K., Gadapati, W., Webb, E., Savitch, L. V., Singh, J., et al. (2012b). The effects of phenotypic plasticity on photosynthetic performance in winter rye, winter wheat and Brassica napus. Physiol. Plant. 144, 169-188. doi: 10.1111/j.1399-3054.2011.01513.x

Dahal, K., Kane, K., Sarhan, F., Grodzinski, B., and Hüner, N. P. A. (2012c). Cold acclimation inhibits $\mathrm{CO}_{2}$-dependent stimulation of photosynthesis in spring wheat and spring rye. Botany 90, 433-444. doi: 10.1139/b2012-007 
Dahal, K., Kane, K., Sarhan, F., Savitch, L. V., Singh, J., Grodzinski, B., et al. (2013a). "C-Repeat transcription factors as targets for the maintenance of crop yield under suboptimal growth conditions," in Handbook of Plant and Crop Physiology, 3rd Edn., ed M. Pessarakli (Boca Raton, FL: Taylor \& Francis Books), 313-332.

Dahal, K., Knowles, V. L., Plaxton, W. C., and Hüner, N. P. A. (2013b). Enhancement of photosynthetic performance, water use efficiency and grain yield during long-term growth under elevated $\mathrm{CO}_{2}$ in wheat and rye is growth temperature and cultivar dependent. Environ. Exp. Bot. doi: 10.1016/j. envexpbot.2013.11.015. (in press).

DeLucia, E. H., Nabity, P. D., Zavala, J. A., and Berenbaum, M. R. (2012). Climate change: resetting plant-insect interactions. Plant Physiol. 160, 1677-1685. doi: 10.1104/pp.112.204750

Demmig-Adams, B., and Adams III, W. W. (1996). The role of xanthophyll cycle carotenoids in the protection of photosynthesis. Trends Plant Sci. 1, 21-26. doi: 10.1016/S1360-1385(96)80019-7

Demmig-Adams, B., Adams III, W. W., Ebbert, V., and Logan, B. A. (1999). "Ecophysiology of the xanthophyll cycle," in Advances in Photosynthesis. The Photochemistry of Carotenoids, Vol. 8, eds H. A. Frank, A. J. Young, G. Britton, and R. J. Cogdell (Dordrecht: Kluwer Academic Publishers), 245-269. doi: 10.1007/0-306-48209-6_14

Dietz, K.-J., Schreiber, U., and Heber, U. (1985). The relationship between the redox state of QA and photosynthesis in leaves at various carbon-dioxide, oxygen and light regimes. Planta 166, 219-226. doi: 10.1007/BF00397352

Dong, C. H., Agarwal, M., Zhang, Y., Xie, Q., and Zhu, J. K. (2006). The negative regulator of plant cold responses, HOS1, is a RING E3 ligase that mediates the ubiquitination and degradation of ICE1. Proc. Natl. Acad. Sci. U.S.A. 103 8281-8286. doi: 10.1073/pnas.0602874103

Drake, B. G., Gonzalez-Meler, M. A., and Long, S. P. (1997). More efficient plants: a consequence of rising atmospheric $\mathrm{CO}_{2}$ ? Annu. Rev. Plant Physiol. Plant Mol. Biol. 48, 609-639. doi: 10.1146/annurev.arplant.48.1.609

Eberhard, S., Finazzi, G., and Wollman, F.-A. (2008). The dynamics of photosynthesis. Annu. Rev. Genetics 42, 463-515. doi: 10.1146/annurev.genet.42.110807. 091452

Edelman, M., and Mattoo, A. K. (2008). D1-protein dynamics in photosystem II: the lingering enigma. Photosynth. Res. 98, 609-620. doi: 10.1007/s11120-0089342-X

Edwards, G. E., Voznesenkaya, V. E., Smith, M., Koteyeva, N. K., Park, Y. I., Park, J H., et al. (2008). "Breaking the paradigm in C4 photosynthesis: does it hold promise for C4 rice?” in Charting New Pathways to C4, eds J. E. Sheehy, P. L. Mitchell, and B. Hardy (World Scientific Publishing Co.), 249-273. doi: 10.1142/9789812709523_0015

Ensminger, I., Busch, F., and Hüner, N. P. A. (2006). Photostasis and cold acclimation: sensing low temperature through photosynthesis. Physiol. Plant. 126, 28-44. doi: 10.1111/j.1399-3054.2006.00627.x

Farage, P. K., Blowers, D., Long, S. P., and Baker, N. R. (2006). Low growth temperatures modify the efficiency of light use by photosystem II for $\mathrm{CO}_{2}$ assimilation in leaves of two chilling-tolerant $\mathrm{C} 4$ species, Cyperus longus $\mathrm{L}$. and Miscanthus giganteus. Plant Cell Environ. 29, 720-728. doi: 10.1111/j.13653040.2005.01460.x

Fernandez, A. P., and Strand, A. (2008). Retrograde signaling and plant stress: plastid signals initiate cellular stress responses. Curr. Opin. Plant Biol. 11, 509-513. doi: 10.1016/j.pbi.2008.06.002

Foyer, C., Furbank, R., Harbinson, J., and Horton, P. (1990). The mechanisms contributing to photosynthetic control of electron transport by carbon assimilation in leaves. Photosynth. Res. 25, 83-100. doi: 10.1007/BF00035457

Foyer, C. H., Ferrario-Mery, S., and Huber, S. C. (2000). "Regulation of carbon fluxes in the cytosol: coordination of sucrose synthesis, nitrate reduction and organic acid and amino acid biosynthesis" in Advances in Photosynthesis. Photosynthesis: Physiology and Metabolism, Vol. 9, eds R. C. Leegood, T. D Sharkey, and S. von Caemmerer (Dordrecht: Kluwer Academic Publishers), 178-203.

Foyer, C. H., and Noctor, G. (2002). "Photosynthetic nitrogen assimilation:interpathway control and signalling," in Advances in Photosynthesis and Respiration. Photosynthetic Nitrogen Assimilation and Associated Carbon Respiratory Metabolism, Vol. 12, eds C. H. Foyer and G. Noctor (Dordrecht: Kluwer Academic Publishers), 1-22. doi: 10.1007/0-306-48138-3_1

Franklin, K. A. (2009). Light and temperature signal crosstalk in plant development. Curr. Opin. Plant Biol. 12, 63-68. doi: 10.1016/j.pbi.2008.09.007
Franklin, K. A., and Whitelam, G. C. (2007). Light-quality regulation of freezing tolerance in Arabidopsis thaliana. Nat. Genet. 39, 1410-1413. doi: 10.1038/ng.2007.3

Gilmour, S. J., Sebolt, A. M., Salazar, M. P., Everard, J. D., and Thomashow, M. F. (2000). Overexpression of the Arabidopsis CBF3 transcriptional activator mimics multiple biochemical changes associated with cold acclimation. Plant Physiol. 124, 1854-1865. doi: 10.1104/pp.124.4.1854

Gorsuch, P. A., Pandey, S., and Atkin, O. K. (2010a). Temporal heterogeneity of cold acclimation phenotypes in Arabidopsis leaves. Plant Cell Environ. 33, 244-258. doi: 10.1111/j.1365-3040.2009.02074.x

Gorsuch, P. A., Pandey, S., and Atkin, O. K. (2010b). Thermal de-acclimation: how permanent are leaf phenotypes when cold-acclimated plants experience warming? Plant Cell Environ. 33, 1124-1137. doi: 10.1111/j.1365-3040.2010. 02134.x

Gray, G. R., Chauvin, L.-P., Sarhan, F., and Hüner, N. P. A. (1997). Cold acclimation and freezing tolerance. A complex interaction of light and temperature. Plant Physiol. 114, 467-474.

Gray, G. R., and Heath, D. (2005). A global reorganization of the metabolome in Arabidopsis during cold acclimation is revealed by metabolic fingerprinting. Physiol. Plant. 124, 236-248. doi: 10.1111/j.1399-3054.2005.00507.x

Gray, G. R., Savitch, L. V., Ivanov, A. G., and Hüner, N. P. A. (1996). Photosystem II excitation pressure and development of resistance to photoinhibition. II. Adjustment of photosynthetic capacity in winter wheat and winter rye. Plant Physiol. 110, 61-71.

Griffith, M., and Yaish, M. W. F. (2004). Antifreeze proteins in overwintering plants: a tale of two activities. Trends Plant Sci. 9, 399-405. doi: 10.1016/j.tplants.2004.06.007

Guy, C. L. (1990). Cold acclimation and freezing tolerance: role of protein metabolism. Annu. Rev. Plant Physiol. Plant Mol. Biol. 41, 187-223. doi: 10.1146/annurev.pp.41.060190.001155

Guy, C. L., Huber, J. L. A., and Huber, S. C. (1992). Sucrose phosphate synthase and sucrose accumulation at low temperature. Plant Physiol. 100, 502-508. doi: 10.1104/pp.100.1.502

Hatfield, J. L., Boote, K. J., and Kimball, B. A. (2011). Climate impacts on agriculture: implications for crop production. Agron. J. 103, 351-370. doi: 10.2134/agronj2010.0303

Hiilovaara-Teijo, M., Hannukkala, A., Griffith, M., Yu, X. M., and PihakaskiMaunsbach, K. (1999). Snow-mold-induced apoplastic proteins in winter rye leaves lack antifreeze activity. Plant Physiol. 121, 665-673. doi: 10.1104/pp.121.2.665

Hopkins, W. G., and Hüner, N. P. A. (2008). Introduction to Plant Physiology, 4th Edn. Hoboken, NJ: Wiley and Sons.

Horton, P. (2000). Prospects for crop improvement through the genetic manipulation of photosynthesis: morphological and biochemical aspects of light capture. J. Exp. Bot. 51, 475-485. doi: 10.1093/jexbot/51.suppl_1.475

Horton, P. (2012). Optimization of light harvesting and photoprotection: molecular mechanisms and physiological consequences. Philos. Trans. R. Soc. B Biol. Sci. 367, 3455-3465. doi: 10.1098/rstb.2012.0069

Horton, P., and Ruban, A. V. (2005). Molecular design of the photosystem II light-harvesting antenna: photosynthesis and photoprotection. J. Exp. Bot. 56, 365-373. doi: 10.1093/jxb/eri023

Horton, P., Ruban, A. V., and Walters, R. G. (1996). Regulation of light harvesting in green plants. Annu. Rev. Plant Physiol. Plant Mol. Biol. 47, 655-684. doi: 10.1146/annurev.arplant.47.1.655

Hsieh, T.-H., Lee, J.-T., Yang, P.-T., Chiu, L.-H., Charng, Y.-Y., Wang, Y.-C., et al. (2002). Heterologous expression of the Arabidopsis C-repeat/dehydration response element binding factor 1 gene confers elevated tolerance to chilling and oxidative stresses in transgenic tomato. Plant Physiol. 129, 1086-1094. doi: $10.1104 / \mathrm{pp} .003442$

Hua, J. (2009). From freezing to scorching, transcriptional responses to temperature variations in plants. Curr. Opin. Plant Biol. 12, 568-573. doi: 10.1016/j.pbi.2009.07.012

Huang, J.-G., Yang, M., Lui, P., Yang, G.-D., Wu, C.-A., and Zheng, C.-C. (2009). GhDREB1 enhances abiotic stress tolerance, delays GA-mediated development and represses cytokinin signalling in transgenic Arabidopsis. Plant Cell Environ. 32, 1132-1145. doi: 10.1111/j.1365-3040.2009.01995.x

Hudson, D., Guevara, D. R., Hand, A. J., Xu, Z., Hao, L., Chen, X., et al. (2013). Rice cytokinin GATA transcription factorl regulates chloroplast development and plant architecture. Plant Physiol. 162, 132-144. doi: 10.1104/pp.113.217265 
Hüner, N. P. A. (1985). Morphological, anatomical and molecular consequences of growth and development at low temperature in Secale cereale L. cv Puma. Am. J. Bot. 73, 1290-1306.

Hüner, N. P. A., Bode, R., Dahal, K., Busch, F. A., Possmayer, M., Szyszka, B., et al. (2013). Shedding some light on cold acclimation, cold adaptation, and phenotypic plasticityl. Botany 91, 127-136. doi: 10.1139/cjb-2012-0174

Hüner, N. P. A., Dahal, K., Hollis, L., Bode, R., Rosso, D., Krol, M., et al. (2012). Chloroplast redox imbalance governs phenotypic plasticity: the "grand design of photosynthesis" revisited. Front. Plant Physiol. 3:255. doi: 10.3389/fpls.2012.00255

Hüner, N. P. A., Elfman, B., Krol, M., and MacIntosh, A. (1984). Growth and development at cold hardening temperatures. Chloroplast ultrastructure, pigment content and composition. Can. J. Bot. 62, 53-60. doi: 10.1139/b84-009

Hüner, N. P. A., and Grodzinski, B. (2011). "Photosynthesis and photoautotroph," in Comprehensive Biotechnology, 2nd Edn., Vol. 1, ed M. Moo-Young (Amsterdam: Elsevier), 315-322. doi: 10.1016/B978-0-08-088504-9.00036-2

Hüner, N. P. A., Öquist, G., Hurry, V. M., Krol, M., Falk, S., and Griffith, M. (1993). Photosynthesis, photoinhibition and low temperature acclimation in cold tolerant plants. Photosynth. Res. 37, 19-39. doi: 10.1007/BF02185436

Hüner, N. P. A., Öquist, G., and Melis, A. (2003). "Photostasis in plants, green algae and cyanobacteria: the role of light harvesting antenna complexes," in Advances in Photosynthesis and Respiration. Light Harvesting Antennas in Photosynthesis, Vol. 13, eds B. R. Green and W. W. Parson (Dordrecht: Kluwer Academic Publishers), 401-421. doi: 10.1007/978-94-017-2087-8_14

Hüner, N. P. A., Oquist, G., and Sarhan, F. (1998). Energy balance and acclimation to light and cold. Trends Plant Sci. 3, 224-230. doi: 10.1016/S13601385(98)01248-5

Hurry, V., Strand. A., Furbank, R., and Stitt, M. (2000). The role of inorganic phosphate in the development of freezing tolerance and the acclimatization of photosynthesis to low temperature is revealed by the pho mutants of Arabidopsis thaliana. Plant J. 24, 383-396. doi: 10.1046/j.1365-313x.2000.00888.x

Hurry, V., Tobiaeson, M., Krömer, S., Gardeström, P., and Öquist, G. (1995). Mitochondria contribute to increased photosynthetic capacity of leaves of winter rye (Secale cereale L.) following cold-hardening. Plant Cell Environ. 18, 69-76. doi: 10.1111/j.1365-3040.1995.tb00545.x

Hurry, V. M., and Hüner, N. P. A. (1991). Low growth temperature affects a differential inhibition of photosynthesis in spring and winter wheat. Plant Physiol. 96, 491-497. doi: 10.1104/pp.96.2.491

Hurry, V. M., and Hüner, N. P. A. (1992). Effects of cold hardening on sensitivity of winter and spring wheat leaves to short-term photoinhibition and recovery of photosynthesis. Plant Physiol. 100, 1283-1290. doi: 10.1104/pp.100.3.1283

Hurry, V. M., Keerberg, O., Pärnik, T., Gardeström, P., and Öquist, G. (1995a). Cold-hardening results in increased activity of enzymes involved in carbon metabolism in leaves of winter rye (Secale cereale L). Planta 195, 554-562. doi: 10.1007/BF00195715

Hurry, V. M., Malmberg, G., Gardeström, P., and Öquist, G. (1994). Effects of a short-term shift to low temperature and of long-term cold hardening on photosynthesis and ribulose-1,5-bisphosphate carboxylase/oxygenase and sucrose phosphate synthase activity in leaves of winter rye (Secale cereale L.). Plant Physiol. 106, 983-990.

Hurry, V. M., Strand, A., Tobiaeson, M., Gardeström, P., and Öquist, G. (1995b). Cold-hardening of spring and winter wheat and rape results in differential effects on growth, carbon metabolism and carbohydrate content. Plant Physiol. $109,697-706$

IPCC. (2007). "Climate change 2007: the physical science basis," in Contribution of Working Group I to the Fourth Assessment Report of the Intergovernmental Panel on Climate Change, eds S. D Solomon, M. Qin, M. Manning, Z. Chen, M. Marquis, K.B. Averyt, et al. (Cambridge, UK: Cambridge University Press).

Jaglo-Ottosen, K. R., Gilmour, S. J., Zarka, D. G., Schabenberger, O., and Thomashow, M. F. (1998). Arabidopsis CBF1 overexpression induces COR genes and enhances freezing tolerance. Science 280, 104-106. doi: 10.1126/science.280.5360.104

Jarvis, P., and Lopez-Juez, E. (2013). Biogenesis and homeostasis of chloroplasts and other plastids. Nat. Rev. Mol. Cell Biol. 14, 787-802. doi: 10.1038/ nrm3702

Kane, K., Dahal, K., Badawi, M. A., Houde, M., Hüner, N. P. A., and Sarhan, F. (2013). Long-term growth under elevated $\mathrm{CO}_{2}$ suppresses biotic stress genes in non-acclimated, but not cold-acclimated winter wheat. Plant Cell Physiol. 54, 1751-1768. doi: 10.1093/pcp/pct116
Kim, C., and Apel, K. (2013). Singlet oxygen-mediated signaling in plants: moving from flu to wild type reveals an increasing complexity. Photosynth. Res. 116, 455-464 doi: 10.1007/s11120-013-9876-4

Knight, H., and Knight, M. R. (2000). Imaging spatial and cellular characteristics of low temperature calcium signature after cold acclimation in Arabidopsis. J. Exp. Bot. 51, 1679-1686. doi: 10.1093/jexbot/51.351.1679

Ko, J.-H., Mitina, I., Tamada, Y., Hyun, Y., Choi, Y., Amasino, R. M., et al. (2010). Growth habit determination by the balance of histone methylation activities in Arabidopsis. EMBO J. 29, 3208-3215. doi: 10.1038/emboj.2010.198

Koussevitzky, S., Nott, A., Mockler, T. C., Hong, F., Sachetto-Martins, G., Surpin, M., et al. (2000). Imaging spatial and cellular characteristics of low temperature calcium signature after cold acclimation in Arabidopsis. J. Exp. Bot. 51, 1679-1686. doi: 10.1093/jexbot/51.351.1679

Krause, G. H. (1988). Photoinhibition of photosynthesis. An evaluation of damaging and protective mechanisms. Physiol. Plant. 74, 566-574. doi: 10.1111/j.13993054.1988.tb02020.x

Krause, G. H. (1994). "Photoinhibition induced by low temperatures," in Photoinhibition of Photosynthesis: from Molecular Mechanisms to the Field, eds N. R. Baker and J. R. Bowyer (Oxford: Bios Scientific), 331-348.

Kulheim, C., Agren, J., and Jansson, S. (2002). Rapid regulation of light harvesting and plant fitness in the field. Science 297, 91-93. doi: 10.1126/science.1072359

Kurepin, L., Dahal, K., Savitch, L., Singh, J., Bode, R., Ivanov, A., et al. (2013). Role of CBFs as integrators of chloroplast redox, phytochrome and plant hormone signaling during cold acclimation. Int. J. Mol. Sci. 14, 12729-12763. doi: $10.3390 /$ ijms 140612729

Lee, C.-M., and Thomashow, M. F. (2012), Photoperiodic regulation of the Crepeat binding factor $(\mathrm{CBF})$ cold acclimation pathway and freezing tolerance in Arabidopsis thaliana. Proc. Natl. Acad. Sci. U.S.A. 109, 15054-15059. doi: 10.1073/pnas.1211295109

Lee, H., Xiong, L., Gong, Z., Ishitani, M., Stevenson, B., and Zhu, J. K. (2001). The Arabidopsis HOS1 gene negatively regulates cold signal transduction and encodes a RING finger protein that displays cold-regulated nucleocytoplasmic partitioning. Genes Dev. 15, 912-924. doi: 10.1101/gad.866801

Leonardos, E. D., Savitch, L. V., Hüner, N. P. A., Öquist, G., and Grodzinski, B. (2003). Daily photosynthetic and C-export patterns in winter wheat leaves during cold stress and acclimation. Physiol. Plant. 117, 521-531. doi: 10.1034/j.1399-3054.2003.00057.x

Levitt, J. (1980). Responses of Plants to Environmental Stresses. Chilling, Freezing, and High Temperature Stresses. New York, NY: Academic Press.

Li, H.-M., Washburn, T., and Chory, J. (1993). Regulation of gene expression by light. Curr. Opin. Cell Biol. 5, 455-460. doi: 10.1016/0955-0674(93)90011-E

Lim, J., Mittler, R., and Chory, J. (2007). Signals from chloroplasts converge to regulate nuclear gene expression. Science 316, 715-719. doi: 10.1126/science. 1140516

Liu, Q., Kasuga, M., Sakuma, Y., Abe, H., Miura, S., Yamaguchi-Shinozaki, K., et al. (1998). Two transcription factors, DREB1 and DREB2, with an EREBP/AP2 DNA binding domain separate two cellular signal transduction pathways in drought- and low-temperature-responsive gene expression, respectively, in Arabidopsis. Plant Cell 10, 1391-1406. doi: 10.1105/tpc.10. 8.1391

Long, S. P., Ainsworth, E. A., Rogers, A., and Ort, D. R. (2004). Rising atmospheris carbon dioxide: plants FACE the future. Annu. Rev. Plant Biol. 55, 591-628. doi: 10.1146/annurev.arplant.55.031903.141610

Long, S. P., Zhu, X.-G., Naidu, S. L., and Ort, D. R. (2006). Can improvement in photosynthesis increase crop yields? Plant Cell Environ. 29, 315-330. doi: 10.1111/j.1365-3040.2005.01493.x

Long, S. P., Humphries S., and Falkowski, P. G. (1994). Photoinhibition of photosynthesis in nature. Annu. Rev. Plant Physiol. Plant Mol. Biol. 45, 633-662. doi 10.1146/annurev.pp.45.060194.003221

Loomis, R. S., and Amthor, J. S. (1999). Yield potential, plant assimilatory capacity, and metabolic efficiencies. Crop Sci. 39, 1584-1596. doi: 10.2135/cropsci1999.3961584x

Los, D., Mironov, K., and Allakhverdiev, S. (2013). Regulatory role of membrane fluidity in gene expression and physiological functions. Photosynth. Res. 116, 489-509. doi: 10.1007/s11120-013-9823-4

Los, D. A., and Murata, N. (2002). "Sensing and responses to low temperature in cyanobacteria," in Sensing, Signalling and Cell Adaptation, eds K. B. Storey and J. M. Storey (Amsterdam: Elsevier Science BV), 139-153. doi: 10.1016/S15681254(02)80012-2 
Magome, H., Yamaguchi, S., Hanada, A., Kamiya, Y., and Oda K. (2004). Dwarf and delayed-flowering 1, a novel Arabidopsis mutant deficient in gibberellin biosynthesis because of overexpression of a putative AP2 transcription factor. Plant J. 37, 720-729. doi: 10.1111/j.1365-313X.2003.01998.x

Medina, J., Bargues, M., Terol, J., Perez-Alonso, M., and Salinas, J. (1999). The Arabidopsis $C B F$ gene family is composed of three genes encoding AP2 domain-containing proteins whose expression is regulated by low temperature but not by abscisic acid or dehydration. Plant Physiol. 119, 463-469. doi: 10.1104/pp.119.2.463

Melis, A. (1999). Photosystem-II damage and repair cycle in chloroplasts: what modulates the rate of photodamage in vivo ? Trends Plant Sci. 4, 130-135. doi: 10.1016/S1360-1385(99)01387-4

Miura, K., Jin, J. B., Lee, J., Yoo, C. Y., Stirm, V., Miura, T., et al. (2007). SIZ1mediated sumoylation of ICE1 controls CBF3/DREB1A expression and freezing tolerance in Arabidopsis. Plant Cell 19, 1403-1414. doi: 10.1105/tpc.106.048397

Miura, K., and Ohta, M. (2010). SIZ1, a small ubiquitin-related modifier ligase, controls cold signalling through the regualtion of salicylic acid accumulation. J. Plant Physiol. 167, 555-560. doi: 10.1016/j.jplph.2009.11.003

Monroy, A. F., Sangwan, V., and Dhindsa, R. S. (1998). Low temperature signal transduction during cold acclimation - protein phosphatase $2 \mathrm{a}$ as an early target for cold-inactivation. Plant J. 13, 653-660. doi: 10.1046/j.1365313X.1998.00070.x

Mullineaux, P. M. and Baker, N. R. (2010). Oxidative Stress: antagonistic signaling for acclimation or cell death? Plant Physiol. 154, 521-525. doi: 10.1104/pp.110.161406

Murata, N., and Los, D. A. (1997). Membrane fluidity and temperature perception. Plant Physiol. 115, 875-879. doi: 10.1104/pp.115.3.875

Murata, N., Takahashi, S., Nishiyama, Y., and Allakhverdiev, S. I. (2007). Photoinhibition of photosystem II under environmental stress. Biochim. Biophys. Acta 1767, 414-421. doi: 10.1016/j.bbabio.2006.11.019

Murchie, E. H., Pinto, M., and Horton, P. (2009). Agriculture and the new challenges for photosynthesis research. New Phytol. 181, 532-552. doi: 10.1111/j.1469-8137.2008.02705.x

NDong, C., Danyluk, J., Hüner, N. P. A., and Sarhan, F. (2001). Survey of gene expression in winter rye during changes in either growth temperature, irradiance or excitation pressure. Plant Mol. Biol. 45, 691-703. doi: 10.1023/A:1010684719225

Niyogi, K. K. (1999). Photoprotection revisited: genetic and molecular approaches. Annu. Rev. Plant Physiol. Plant Mol. Biol. 50, 333-359. doi: 10.1146/annurev.arplant.50.1.333

Nott, A., Jung, H.-S., Koussevitzky, S., and Chory, J. (2006). Plastid-tonucleus retrograde signalling. Annu. Rev. Plant Biol. 57, 739-759. doi: 10.1146/annurev.arplant.57.032905.105310

Oliver, S. N., Finnegan, E. J., Dennis, E. S., Peacock, W. J., and Trevaskis, B. (2009). Vernalization-induced flowering in cereals is associated with changes in histone methylation at the VERNALIZATION1 gene. Proc. Natl. Acad. Sci. U.S.A. 106, 8386-8391. doi: 10.1073/pnas.0903566106

Öquist, G., and Hüner, N. P. A. (2003). Photosynthesis of overwintering evergreen plants. Annu. Rev. Plant Biol. 54, 329-355. doi: 10.1146/annurev.arplant.54.072402.115741

Orvar, B. L., Sangwan, V., Omann, F., and Dhindsa, R. S. (2000). Early steps in cold sensing by plant cells: the role of actin cytoskeleton and membrane fluidity. Plant J. 23, 785-794. doi: 10.1046/j.1365-313x.2000.00845.x

Osmond, C. B. (1994). "What is photoinhibition? Some insights from comparison of shade and sun plants," in Photoinhibition of Photosynthesis-from Molecular Mechanisms to the Field, eds N. R. Baker and J. R. Bowyer (Oxford: Bios Scientific Publishers), 1-24.

Peng, J., Carol, P., Richards, D. E., King, K. E., Cowling, R. J., Murphy, G. P., et al. (1997). The Arabidopsis GAI gene defines a signalling pathway that negatively regulates gibberellin responses. Genes Dev. 11, 3194-3205. doi: 10.1101/gad.11.23.3194

Peng, J., and Harberd, N. P. (1997). Giberellin deficiency and response mutations suppress stem elongation phenotype of phytochrome-deficient mutants of Arabidopsis. Plant Physiol. 113, 1051-1058. doi: 10.1104/pp.113.4.1051

Peng, J., Richards, D. E., Hartley, N. M., Murphy, G. P., Devos, K. M., Flintham, J. E., et al. (1999). 'Green revolution' genes encode mutant gibberellin response modulators. Nature 400, 256. doi: 10.1038/22307

Pfannschmidt, T. (2003). Chloroplast redox signals: how photosynthesis controls its own genes. Trends Plant Sci. 8, 33-41. doi: 10.1016/S1360-1385(02)00005-5
Plieth, C., Hansen, U. P., Knight, H., and Knight, M. R. (1999). Temperature sensing by plants: the primary characteristics of signal perception and calcium response. Plant J. 18, 491-497. doi: 10.1046/j.1365-313X.1999.00471.x

Pocock, T. H., Hurry, V., Savitch, L. V., and Hüner, N. P. A. (2001). Susceptibility to low-temperature photoinhibition and the acquisition of freezing tolerance in winter and spring wheat: the role of growth temperature and irradiance. Physiol. Plant. 113, 499-506. doi: 10.1034/j.1399-3054.2001.1130408.x

Pogson, B. J., Woo, N. S., Förster, B., and Small, I. D. (2008). Plastid signalling to the nucleus and beyond. Trends Plant Sci. 13, 602-609. doi: 10.1016/j.tplants.2008.08.008

Pollock, C. J., and Cairns, A. J. (1991). Fructan metabolism in grasses and cereals. Annu. Rev. Plant Physiol. Plant Mol. Biol. 42, 77-101. doi: 10.1146/annurev.pp.42.060191.000453

Powell, N., Ji, X., Ravash, R., Edlington, J., and Dolferus, R. (2012). Yield stability for cereals in a changing climate. Funct. Plant Biol. 39, 539-552. doi: 10.1071/FP12078

Powles, S. B. (1984). Photoinhibition of photosynthesis induced by visible light. Annu. Rev. Plant Physiol. 35, 14-44. doi: 10.1146/annurev.pp.35.060184.000311

Rapacz, M., Wolanin, B., and Hura, K. (2008). The effects of cold acclimation on the photosynthetic apparatus and the expression of COR $14 \mathrm{~b}$ in four genotypes of barley (Hordeum vulgare) contrasting in their tolerance to freezing and high light treatment in cold conditions. Ann. Bot. 101, 689-699. doi: 10.1093/aob/mcn008

Rosso, D., Bode, R., Li, W., Krol, M., Saccon, D., Wang, S., et al. (2009). Photosynthetic redox imbalance governs leaf sectoring in the Arabidopsis thaliana variegation mutants immutans, spotty, var1, and var2. Plant Cell 21, 3473-3492. doi: 10.1105/tpc.108.062752

Sakamoto, W., Miyagishima, S.-Y., and Jarvis, P. (2008). Chloroplast biogenesis: control of plastid development, protein import, division and inheritance. The Arabidopsis Book 6:e0110. doi: 10.1199/tab.0110

Sane, P. V., Ivanov, A. G., Öquist, G., and Hüner, N. P. A. (2012). "Thermoluminescence," in Advances in Photosynthesis and Respiration. Photosynthesis: Plastid Biology, Energy Conversion and Carbon Assimilation, Vol. 34, eds J. J. Eaton-Rye, B. C. Tripathy, and T. D. Sharkey (Dordrecht: Springer Science), 445-474.

Sarhan, F., Ouellet, F., and Vazquez-Tello, A. (1997). The wheat wcs120 gene family. A useful model to understand the molecular genetics of freezing tolerance in cereals. Physiol. Plant. 101, 439-445. doi: 10.1111/j.1399-3054.1997. tb01019.x

Savitch, L. V., Allard, G., Seki, M., Robert, L. S., Tinker, N. A., Hüner, N. P. A., et al. (2005). The effect of over-expression of two Brassica CBF/DREB1-like transcription factors on photosynthetic capacity and freezing tolerance in Brassica napus. Plant Cell Physiol. 46, 1525-1539. doi: 10.1093/pcp/pci165

Savitch, L. V., Harney, T., and Hüner, N. P. A. (2000a). Sucrose metabolism in spring and winter wheat in response to high irradiance, cold stress and cold acclimation. Physiol. Plant. 108, 270-278. doi: 10.1034/j.1399-3054.2000.108003270.x

Savitch, L. V., Massacci, A., Gray, G. R., and Hüner, N. P. A. (2000b). Acclimation to low temperature or high light mitigates sensitivity to photoinhibition: roles of the Calvin cycle and the Mehler reaction. Aust. J. Plant Physiol. 27, 253-264. doi: 10.1071/PP99112

Seo, E., Lee, H., Jeon, J., Park, H., Kim, J., Noh, Y.-S., et al. (2009). Crosstalk between cold response and flowering in Arabidopsis is mediated through the flowering-time gene SOC1 and its upstream negative regulator FLC. Plant Cell 21, 3185-3197. doi: 10.1105/tpc.108.063883

Sharkey, T. D., and Vanderveer, P. J. (1989). Stromal phosphate concentration is low during feedback limited photosynthesis. Plant Physiol. 91, 679-684. doi: 10.1104/pp.91.2.679

Spreitzer, R. J., and Salvucci, M. E. (2002). Rubisco: structure, regulatory interactions, and possibilities for a better enzyme. Annu. Rev. Plant Biol. 53, 449-475. doi: 10.1146/annurev.arplant.53.100301.135233

Steponkus, P. L. (1984). Role of the plasma membrane in freezing injury and cold acclimation. Annu. Rev. Plant Physiol. 35, 543-584. doi: 10.1146/annurev.pp.35.060184.002551

Stitt, M., and Hurry, V. (2002). A plant for all seasons: alterations in photosynthetic carbon metabolism during cold acclimation in Arabidopsis. Curr. Opin. Plant Biol. 5, 199-206. doi: 10.1016/S1369-5266(02)00258-3

Stitt, M., and Quick, W. P. (1989). Photosynthetic carbon partitioning: its regulation and possibilities for manipulation. Plant Physiol. 77, 633-641. doi: 10.1111/j.1399-3054.1989.tb05402.x 
Strand, A., Foyer, C. H., Gustafsson, P., Gardeström, P., and Hurry, V. (2003). Altering flux through the sucrose biosynthesis pathway in transgenic Arabidopsis thaliana modifies photosynthetic acclimation at low temperatures and the development of freezing tolerance. Plant Cell Environ. 26, 523-535. doi: 10.1046/j.1365-3040.2003.00983.x

Strand, A., Hurry, V., Henkes, S., Hüner, N. P. A., Gustafsson, P., Gardeström, P., et al. (1999). Acclimation of Arabidopsis leaves developing at low temperatures. Increasing cytoplasmic volume accompanies increased activities of enzymes in the Calvin cycle and in the sucrose-biosynthesis pathway. Plant Physiol. 119, 1387-1397. doi: 10.1104/pp.119.4.1387

Sung, S., and Amasino, R. M. (2005). Remembering winter: toward a molecular understanding of vernalization. Annu. Rev. Plant Biol. 56, 491-508. doi: 10.1146/annurev.arplant.56.032604.144307

Takahashi, S., and Murata, N. (2008). How do environmental stresses accelerate photoinhibition? Trends Plant Sci. 13, 178-182. doi: 10.1016/j.tplants.2008. 01.005

Tcherkez, G. G. B., Farquhar, G. D., and Andrews, T. J. (2006). Despite slow catalysis and confused substrate specificity, all ribulose bisphosphate carboxylases may be nearly perfectly optimized. Proc. Natl. Acad. Sci. U.S.A. 103, 7246-7251. doi: $10.1073 /$ pnas.0600605103

Theocharis, A., Clemente, C., and Barka, E. A. (2012). Physiological and molecular changes in plants grown at low temperatures. Planta 235, 1091-1105. doi: 10.1007/s00425-012-1641-y

Thomashow, M. F. (2001). So what's new in the field of plant cold acclimation? Lots! Plant Physiol. 125, 89-93. doi: 10.1104/pp.125.1.89

Thomashow, M. F. (2010). Molecular basis of plant cold acclimation: insights gained from studying the CBF cold response pathway. Plant Physiol. 154, 571-577 doi: 10.1104/pp.110.161794

Trevaskis, B. (2010). The central role of the VERNALIZATION1 gene in the vernalization response of cereals. Funct. Plant Biol. 37, 479-487. doi: 10.1071/ FP10056

UN Report. (2011). World Population Prospects: The 2010 Revision, Highlights and Advance Tables. United Nations, Department of Economic and Social Affairs, Population Division. ESA/P/WP.220.

Vandegeer, R., Miller, R. G., and Bain, M. (2012). Drought adversely affects tuber development and nutritional quality of the staple crop cassava (Manihot esulenta Crantz). Funct. Plant Biol. 40, 195-200. doi: 10.1071/FP12179

Waters, M. T., and Langdale, J. A. (2009). The making of a chloroplast. EMBO J. 28, 2861-2873. doi: 10.1038/emboj.2009.264
Wilson, K. E., Ivanov, A. G., Öquist, G., Grodzinski, B., Sarhan, F., and Hüner, N.P.A. (2006). Energy balance, organellar redox status and acclimation to environmental stress. Can. J. Bot. 84, 1355-1370. doi: 10.1139/B06-098

Woodson, J. D., and Chory, J. (2008). Coordination of gene expression between organellar and nuclear genomes. Nat. Rev. Genet. 9, 383-395. doi: $10.1038 / \operatorname{nrg} 2348$

Xin, Z. (2002). "Acquired freezing tolerance in higher plants: the sensing and molecular responses to low nonfreezing temperatures," in Sensing, Signalling and Cell Adaptation, Vol. 3, eds K. B. Storey and J. M. Storey (Amsterdam: Elsevier Science BV), 121-137.

Zarka, D. G., Vogel, J. T., Cook, D., and Thomashow, M. F. (2003). Cold induction of Arabidopsis CBF genes involves multiple ICE (Inducer of CBF Expression) promoter elements and a cold-regulatory circuit that is desensitized by low temperature. Plant Physiol. 133, 910-918. doi: 10.1104/pp.103.027169

Zhu, J., Shi, H., Lee, B.-H., Damsz, B., Cheng, S., Stirm, V., et al. (2004). An Arabidopsis homeodomain transcription factor gene, HOS9, mediates cold tolerance through a CBF-independent pathway. Proc. Natl. Acad. Sci. U.S.A. 101, 9873-9878. doi: 10.1073/pnas.0403166101

Zhu, X.-G., Long, S. P., and Ort, D. R. (2010). Improving photosynthetic efficiency for greater yield. Annu. Rev. Plant Biol. 61, 235-261. doi: 10.1146/annurevarplant-042809-112206

Conflict of Interest Statement: The authors declare that the research was conducted in the absence of any commercial or financial relationships that could be construed as a potential conflict of interest.

Received: 14 January 2014; accepted: 25 March 2014; published online: 17 April 2014. Citation: Hüner NPA, Dahal K, Kurepin LV, Savitch L, Singh J, Ivanov AG, Kane $K$ and Sarhan $F$ (2014) Potential for increased photosynthetic performance and crop productivity in response to climate change: role of CBFs and gibberellic acid. Front. Chem. 2:18. doi: 10.3389/fchem.2014.00018

This article was submitted to Agricultural Biological Chemistry, a section of the journal Frontiers in Chemistry.

Copyright (C) 2014 Hüner, Dahal, Kurepin, Savitch, Singh, Ivanov, Kane and Sarhan. This is an open-access article distributed under the terms of the Creative Commons Attribution License (CC BY). The use, distribution or reproduction in other forums is permitted, provided the original author(s) or licensor are credited and that the original publication in this journal is cited, in accordance with accepted academic practice. No use, distribution or reproduction is permitted which does not comply with these terms. 